\title{
Transferencia Condicionada de Ingresos en Argentina: una mirada hacia los orígenes de la Asignación Universal por Hijo para la Protección Social (AUHPS)
}

\section{Conditional Income Transfer in Argentina: a look at the origins of the Universal Child Allowance for Social Protection (UCASP)}

\author{
Melisa Cristina Vargas \\ Universidad Nacional de San Juan (UNSJ) (República Argentina) \\ ORCID: https://orcid.org/0000-0002-8402-9155 \\ melyvargas.mv@gmail.com
}

\section{NOTA BIOGRÁFICA}

Licenciada en Ciencias Políticas. Maestranda en Política Social. Docente en Facultad de Ciencias Sociales, Universidad Nacional de San Juan.

\section{RESUMEN}

El objeto del presente trabajo es analizar una política particular de transferencia condicionada de ingresos: la Asignación Universal por Hijo para la Protección Social (AUHPS), implementada en Argentina en el año 2009 por la entonces presidenta Cristina Fernández de Kirchner, a través del Decreto de Necesidad y Urgencia N. ${ }^{\circ}$ 1602/09, como un subsistema no contributivo dentro del Régimen de Asignaciones Familiares instituido por la Ley N.․ 24.714 y bajo jurisdicción de la Administración Nacional de la Seguridad Social (ANSES).

El estudio, metodológicamente basado en el análisis documental, se estructura en torno a una serie de ejes que son imprescindibles examinar de la AUHPS, entre ellos: los antecedentes regionales, el contexto previo a su surgimiento, los aspectos jurídicos normativos que la respaldan, los sujetos de derecho, las consideraciones y debates del feminismo y la mirada peyorativa de los sectores conservadores más reaccionarios que se manifiestan en contra de este tipo de política social que tiende a equiparar en derechos a los hijos e hijas de los trabajadores formales tanto con los de los trabajadores informales como con los de aquellos que se encuentran circunstancialmente desempleados.

\section{PALABRAS CLAVE}

Políticas Sociales; Programas de Transferencia Condicionada de Ingresos; Asignación Universal por Hijo para la Protección Social; Kirchnerismo; Argentina.

\footnotetext{
ABSTRACT

The purpose of this paper is to analyze a particular policy of conditional transfer of income: Universal Assignment for Child for Social Protection (UCASP), implemented in Argentina in 2009 by the then President Cristina Fernández de Kirchner, through the Decree of Need and Urgency N. ${ }^{\circ} 1602 / 09$, as a non-contributory subsystem within the Family Allowances Regime instituted by Law N. ${ }^{\circ} 24,714$ and under the jurisdiction of the National Social Security Administration (ANSES).

The study, methodologically based on the documentary analysis, is structured around a series of axes that are essential to examine the AUHPS, among them: the regional antecedents, the context prior to its
} 
emergence, the normative juridical aspects that support it, the subjects of law, the considerations and debates of feminism and the pejorative view of the most reactionary conservative sectors that demonstrate against this type of social policy that tends to equate in rights to the sons and daughters of formal workers both with those of informal workers as with those of those who are circumstantially unemployed.

\section{KEYWORDS}

Social Politics; Conditional Cash Transfer Programs; Universal Assignment by Child for Social Protection; Kirchnerism; Argentina.

\section{SUMARIO}

1. INTRODUCCIÓN. 2. PROGRAMAS DE TRANSFERENCIA CONDICIONADA DE INGRESOS: CONCEPTUALIZACIÓN Y ANTECEDENTES EN AMÉRICA LATINA. 3. PTCI EN ARGENTINA: EL CONTEXTO PREVIO AL SURGIMIENTO DE LA AUHPS. 4. LA AUHPS EN ARGENTINA: SURGIMIENTO Y MARCO NORMATIVO. 5. LOS NIÑOS, NIÑAS Y ADOLESCENTES COMO SUJETOS DE DERECHO DE LAAUHPS. 6. LAS CONSIDERACIONES Y DEBATES DEL FEMINISMO SOBRE LAAUHPS. 7. LA MIRADA PEYORATIVA DE LOS SECTORES CONSERVADORES SOBRE LAAUHPS Y LA DESMITIFICACIÓN DE SUS PREJUICIOS. REFLEXIONES FINALES. REFERENCIAS BIBLIOGRÁFICAS.

\section{INTRODUCCIÓN}

Las nuevas nociones de protección social que emergieron en los inicios del kirchnerismo le atribuyeron un papel central al Estado como garante de derechos y regulador del mercado de trabajo (González, 2012).

En los gobiernos de Néstor Kirchner (2003-2007) y de Cristina Fernández de Kirchner (2007-2015) tanto la retórica como la praxis política fueron la antítesis de aquellas predominantes durante el neoliberalismo de los años noventa. Las políticas impulsadas en 12 años de kirchnerismo se orientaron a reconstruir el tejido social y a subsanar las graves consecuencias heredadas del modelo individualista que colapsó en el año 2001. En materia de política social, ello significó la construcción de un sistema protectorio que extendió derechos a quienes, durante la hegemonía neoliberal, habían permanecido invisibilizados por el Estado.

En el campo de las asignaciones familiares afloró como novedad el rediseño del esquema contributivo vigente desde 1957 para los trabajadores registrados con hijos e hijas a cargo. En el año 2009 se anexó a él un subsistema no contributivo al que se denominó: «Asignación Universal por Hijo para la Protección Social» (AUPHPS), destinado a aquellos trabajadores con carga de familia que se desempeñaban en la economía informal o se encontraban transitoriamente desocupados. Según sostiene Bertranou (2010) para el primer grupo la asignación pretende reforzar el ingreso ya que éste, producto de las condiciones informales, suele estar muy por debajo de los valores establecidos como salario mínimo, vital y móvil. Mientras que para los desempleados/as, el ingreso que provee esta intervención social representa un piso que aleja a los miembros del núcleo familiar de la emergencia alimentaria y de la indigencia.

La AUHPS si bien se inscribe en la línea de las típicas políticas de transferencias condicionadas de ingresos que prevalecieron en Latinoamérica durante las últimas décadas, se diferencia de aquellas en la sujeción al esquema de Seguridad Social. Esta intervención está basada en una concepción de justicia social que busca igualar, en dignidad y derechos, a los hijos e hijas de los trabajadores argentinos, cualquiera sea el régimen laboral en el que éstos se desempeñen, mediante una transferencia mensual de ingresos que les garantice un mínimo de subsistencia.

El leitmotiv que guía el presente trabajo es la intención de participar del debate teórico sobre los Programas de Transferencias Condicionadas de Ingresos y, de este modo, efectuar un aporte a la discusión científica en el campo de las políticas sociales.

En este marco, la propuesta es realizar un estudio cualitativo de tipo exploratorio-descriptivo, metodológicamente sustentado en el análisis documental. Según Tancara (1993) este tipo de metodología se vale de una serie de métodos y técnicas para la búsqueda, procesamiento y almacenamiento de la información contenida en diversos documentos a fin de facilitar la presentación sistemática, coherente y argumentada de nueva información en un texto científico. 
En función de lo anterior, el presente artículo se nutre tanto de la producción teórica existente como de los instrumentos jurídicos normativos y de los fundamentos técnicos axiológicos que dieron origen a la AUHPS, elementos que son tensionados y puestos en discusión, a fin de realizar una lectura del fenómeno bajo estudio.

El aporte principal reside en el tratamiento de tres núcleos centrales que se suman al debate preexistente sobre la AUHPS: la protección de la infancia, la cuestión del cuidado y los prejuicios en torno a esa política social.

Con esa finalidad, el trabajo se estructura del siguiente modo: exploración de antecedentes regionales, reseña del contexto previo a su surgimiento, análisis de los aspectos jurídicos normativos que respaldan la AUHPS, consideración de los nuevos sujetos de derecho, debates del feminismo en torno a esa intervención social y exposición de las miradas peyorativas de los sectores conservadores más reaccionarios que se manifiestan en contra de este tipo de política.

\section{PROGRAMAS DE TRANSFERENCIA CONDICIONADA DE INGRESOS: CONCEPTUALIZACIÓN Y ANTECEDENTES EN AMÉRICA LATINA}

En los albores del siglo XXI los Programas de Transferencia Condicionada de Ingresos ${ }^{1}$ (PTCl) se trasformaron en una estrategia política común de varios países latinoamericanos, impulsados con finalidad compartida de mitigar las consecuencias del modelo neoliberal que subsumió a la mayoría de los ciudadanos en la pobreza e indigencia, logrando niveles históricos de desigualdad social en todo el continente.

La importancia de estos programas reside en que son parte de una nueva generación de política social que se articula con otras políticas preexistentes (Martínez Franzoni y Voorend, 2008). Su objeto central es emplear la asistencia material como estímulo para que núcleos familiares en situación de pobreza utilicen la oferta pública de servicios educativos y sanitarios (Villatoro, 2007).

Si bien los diseños contienen particularidades que varían de un país a otro, comparten dos características elementales: la transferencia monetaria a familias con hijos e hijas a cargo y la exigencia de condicionalidades en el ámbito escolar y sanitario con la pretensión de invertir en capital humano y de este modo detener la reproducción de pobreza (Rodríguez Enríquez, 2011).

En un sentido amplio la noción de capital humano incorpora los niveles de educación, salud y nutrición de la población. La pretensión de dotar de esos activos a los destinatarios de la intervención social responde a la aspiración de integrarlos a las relaciones de mercado (Perry et al., 2006).

El derrotero primigenio que moviliza a políticas de esta tipología, impulsadas por organismos financieros internacionales -tales como el Banco Mundial (BM) y el Banco Interamericano de Desarrollo (BID)- es la construcción de puentes o instrumentos al servicio de la reproducción del capitalismo (Cena y Chahbenderian, 2015).

De acuerdo con ello, la hipótesis de quienes adscriben a la teoría del capital humano es que una población sana, alimentada y educada tendrá mayores posibilidades de inserción laboral a futuro. Esa ambición que orienta a los PTCl hace que las condicionalidades aparezcan como un requisito «sine qua non», situación que obliga a las familias al cumplimiento estricto de ellas. En otras palabras, éstas:

Se conciben de manera punitiva, es decir, su falta de cumplimiento implica la pérdida (total o parcial, más o menos automática) del beneficio. Esta imposición se considera necesaria para garantizar el cumplimiento efectivo de la condicionalidad, y en consecuencia la correcta inversión de la población pobre en su propio capital humano (Rodríguez Enríquez, 2011: 11).

Cena y Chahbenderian (2015) destacan que los PTCI al leer la pobreza como una responsabilidad puramente individual y, en última instancia, del núcleo familiar, se inscriben en una mirada simplista que encubre lo sistémico.

En ese orden de cosas, «El problema de este tipo de intervenciones gubernamentales radica en que la base de su diagnóstico sobre la cuestión social a abordar invisibiliza las condiciones estructurales que llevaron a tal estado de cosas» (Cena y Chahbenderian, 2015: 128).

1 En el campo de las políticas sociales, esta tipología de intervenciones también suelen denominarse "Programas de Transferencias Condicionadas de Recursos" (PTMR), "Programas de Transferencias Monetarias Condicionadas" (PTMC), "Programas de Renta Condicionada" (PRC), "Transferencia en Efectivo Condicionadas" (TEC), etc. 
A pesar de las especificidades que los PTCl asumen en cada país, Villatoro (2007) observa que todas las iniciativas de la región se inspiran en cinco bases conceptuales comunes:

1. Búsqueda de eficiencia y equidad (un gasto público mínimo permitiría la reducción o alivio de la pobreza en el corto plazo y el desarrollo del capital humano en el largo plazo).

2. Énfasis en la corrección de las fallas del mercado a partir de crear incentivos a la demanda (condicionalidades).

3. Uso de un enfoque multidimensional que requiere la coordinación de diversos actores institucionales intervinientes.

4. Rol central de las mujeres beneficiarias con la intención de su empoderamiento; y

5. Sistemas de monitoreo y evaluación para incrementar la transparencia.

La literatura existente en la materia documenta que los PTCI son políticas focalizadas pero a su vez con una amplia cobertura. La focalización refiere a que éstos se centran en una población objetivo determinada, aunque ésta sea muy voluminosa (Rodríguez Enríquez, 2011).

Otras de sus notas distintivas son la centralización (las condiciones son definidas en esquemas de «arriba-abajo») y la transitoriedad por cuanto se encuentran atados a ciertas particularidades cuya superación es causal de egreso del programa. En este último plano no hay criterios homogéneos en la región, de modo que pueden presentarse al menos tres formas: egreso por superación de pobreza (se obtiene al conquistar cierto umbral), egreso en función de reglas de transición (conjuga límites pre-definidos con un esquema de superación de pobreza y transferencias decrecientes); y egreso automático una vez cumplido un determinado tiempo de permanencia. Generalmente, éste último tipo está vinculado a la edad de los hijos de los beneficiarios, quienes -en la mayoría de los casos- no deben superar los 18 años (Villatoro, 2007).

Los países que optaron por impulsar estrategias de este tipo alcanzaron resultados satisfactorios al menos en lo inherente al objeto de atenuar los efectos de la pobreza en el corto plazo. Siguiendo a Hevia (2016) conviene subrayar que, para potenciar los resultados exitosos que los PTCI han logrado demostrar en estas décadas, es necesario enfrentar dos riesgos derivados de su diseño e implementación: el de sinécdoque y el del aumento en la asimetría de poder ${ }^{2}$.

El primer riesgo tiene que ver con la confusión de la parte (el programa específico) con el todo (la política social en general). En Latinoamérica los PTCl ostentan -en función de su cobertura, presupuesto y reconocimiento- un elevado peso relativo como estrategia de combate a la pobreza. No obstante, esta centralización en un único modo de intervención tiene tres consecuencias: la limitación de enfrentar la pobreza (multidimensional en sus causas y manifestaciones) con un único programa, la tendencia de los gobiernos a sobrecargar en ellos cada vez más elementos y responsabilidades; y la desarticulación con el resto de la política social. El segundo riesgo refiere a que la operación de los programas en el orden local pueden aumentar la brecha de poder entre agentes estatales y beneficiarios pobres a partir de dos dispositivos: la focalización y las condicionalidades. En orden a evitar las distorsiones que pueden surgir de la práctica de intermediarios u operadores locales, la tendencia es incorporar "candados» que constituyen una suerte de freno a la discrecionalidad de los agentes, entre ellos: mecanismos estandarizados de comunicación, instrumentos de control, sistemas de auditoría, etc. (Hevia, 2016).

En Latinoamérica la mayoría de los gobiernos, independientemente de su signo político, adoptaron PTCl con un doble objetivo: atender tanto a familias afectadas por choques económicos como aquellas en situación de pobreza persistente (Villatoro, 2007). Un estudio de Lo Vuolo (2009) registra la implementación de más de $35 \mathrm{PTCl}$ en 19 países de la región. En tanto que, en un trabajo posterior, Cecchini y Atuesta (2017) documentan la existencia de 30 transferencias monetarias en 20 países latinoamericanos ${ }^{3}$, números que evidencian la centralidad que adquirieron como estrategia para la superación de la pobreza.

Las transferencias monetarias «son un producto genuinamente latinoamericano» (Cecchini y Atuesta, 2017: 15). Dos de los programas más emblemáticos, por su trayectoria y cobertura, son el "Oportunidades" de México y el "Bolsa Familia" de Brasil (Lo Vuolo, 2009).

2 El autor profundiza en detalle cómo se comportan esos riesgos en una intervención específica de México, sin embargo, esa lectura es extensibles a todos los PTCl. Para ahondar en esta línea véase su trabajo titulado: "Los riesgos de los programas de transferencia condicionadas y la construcción de ciudadanía: el caso de Progresa/Oportunidades de México".

3 Una posible explicación de la variación de esos números es la absorción o unificación de algunos PTCl implementados en la región.

4 Este programa perdió vigencia en el año 2014 al ser reemplazado por el Programa "Prospera" que si bien mantiene las prestaciones de su antecesor adicionalmente pretende articular y coordinar la oferta institucional de programas, especialmente con aquellos 
Oportunidades, frecuentemente catalogado como un programa neoliberal por excelencia (Molyneux, 2006), nace en el año 2002 por iniciativa del entonces presidente mexicano Vicente Fox. Su precedente inmediato fue el Programa de Educación, Salud y Alimentación (PROGRESA) impulsado cinco años antes por su antecesor Ernesto Zedillo, experiencia que, aunque se implementó de forma centralizada y con una cobertura restringida sólo a familias en situación de pobreza alimentaria de zonas rurales, se constituyó en un faro orientador para las políticas sociales de esta tipología tanto en el país como en la región (Villatoro, 2007) (Cecchini y Atuesta, 2017).

Hevia De la Jara (2009) destaca que la originalidad de PROGRESA fue su pretensión de morigerar la pobreza en el país mediante transferencias económicas y reunir en un mismo programa varias dimensiones (entre ellas salud, alimentación y educación) con la intención manifiesta de crear el capital humano necesario que le garantice a las generaciones venideras la inserción en el mercado de trabajo.

El autor documenta que regularmente el programa se sometía a evaluaciones externas de impacto que determinaron no solo la necesidad de profundizar la inversión en capital humano a partir de la ampliación de destinatarios sino también la de añadir otros componentes que pretendían reforzar el camino iniciado en 1997:

El cambio de Progresa a Oportunidades en 2002 no fue sólo una mudanza de nombre. Por medio de una «etnografía institucional» pueden distinguirse cuatro diferencias entre estos programas: nuevos objetivos, componentes y estructura administrativa; ampliación a zonas urbanas; mayor incorporación por «densificación»; y nuevas formas de relación entre los beneficiarios y el Programa (Hevia De la Jara, 2009: 43).

Por su parte, "Bolsa Familia" responde a una auténtica apuesta del entonces presidente de la República Federativa de Brasil, Luiz Inácio Lula da Silva, originada en el año $2003^{5}$. Consistía en una transferencia a las familias en situación de pobreza e indigencia a cambio de contraprestaciones educativas y de salud. Su diseño se construye sobre la base de una serie de políticas sociales descentralizadas que, desde mediados de los noventa, eran operadas por municipios (Villatoro, 2007).

Programas como "Bolsa Alimentação", "Cartão Alimentação", "Bolsa Escola” y “Auxilio-Gás", entre otros, fueron absorbidos por el "Bolsa Familia" con el objeto de disminuir la desigualdad y la pobreza mediante la provisión de activos e incentivos que produzcan la ruptura del ciclo vicioso de transmisión intergeneracional que caracterizaba a la historia económica y social del país (Del Tedesco Lins, 2010).

La intención principal que motivó tal unificación fue resolver una serie de dificultades acuciantes derivadas del manejo municipal, entre ellas: la fragmentación institucional, las duplicaciones de beneficiarios y las ineficiencias en la administración (Villatoro, 2007).

El "Bolsa Familia" constituye una política social con una enorme repercusión no sólo por su nivel de cobertura social sino también por sus impactos. Cecchini y Atuesta (2017) al comparar este PTCl con otras iniciativas latinoamericanas señalan que constituye la más importante en la región. En tanto que Dilma Rousseff, al medir esa experiencia con otras similares a nivel global, señaló que es «el más grande programa de inclusión social del mundo» porque permitió sacar a 36 millones de brasileros de la pobreza extrema ${ }^{6}$.

\section{PTCI EN ARGENTINA: EL CONTEXTO PREVIO AL SURGIMIENTO DE LA AUHPS}

La crisis política, económica, institucional y social que estalló en el año 2001 en Argentina, producto del agotamiento del modelo económico, vigente durante la hegemonía neoliberal, provocó una cruenta ruptura del tejido social en materia de bienestar. Los elevados índices de pobreza y desempleo heredados de ese modelo, como consecuencia directa de las políticas de ajuste y reforma estructural, demandaban con urgencia un giro en materia de política social.

En los años previos al estallido de la crisis había cobrado una creciente notoriedad pública la protesta social dirigida por el llamado "Movimiento de Piqueteros" que nucleaba a sectores cruelmente castigados por

relacionados al fomento productivo, la generación de ingresos, el bienestar económico y la inclusión financiera y laboral (CECCHINI Y ATUESTA, 2017).

5 El 9 de enero del año 2004 se transformó en Ley N. ${ }^{\circ}$ 10.836. Disponible en: http://www.planalto.gov.br/ccivil_03/_ato20042006/2004/lei//10.836.htm.

6 Ver nota publicada en página 12 en su edición del día 31 de octubre del año 2013. 
el neoliberalismo, esto es, a trabajadores que quedaron desempleados fruto de la destrucción paulatina de la industria y de los procesos privatizadores de la década del noventa.

El Movimiento de Piqueteros introdujo un novedoso método de protesta materializado principalmente en la quema de neumáticos y en sucesivos e inesperados cortes de ruta en los accesos principales a las ciudades; accionar motivado por el anhelo de visibilizar sus demandas de trabajo y de políticas que permitan atenuar la crítica situación económica que atravesaban a raíz de la interrupción abrupta de sus trayectorias laborales.

Carlos Vilas (2011) al analizar la composición de este nuevo actor social referencia como característica relevante que los trabajadores desempleados que lo integraban tenían prácticas de tipo gremial y/o política internalizadas y aportaron en la negociación con el gobierno ese "capital social» de sus experiencias de organización y conducción. Ello permitió que muchos de los programas sociales o planes de empleo de emergencia de esa época recayeran en la órbita del Movimiento de Piqueteros.

En este marco, luego de la crisis institucional producto de la acefalía presidencial que había provocado la renuncia del entonces presidente Fernando De La Rúa en diciembre del año 2001 y de la maratónica sucesión que abarcó, en un lapso inusual de días, la asunción y renuncia consecutiva de los presidentes Ramón Puerta, Adolfo Rodríguez Saá y Eduardo Camaño, finalmente asume la titularidad del Poder Ejecutivo Eduardo Duhalde.

La crítica situación económica de ese momento sumado a la herencia neoliberal (desempleo, pobreza, marginalidad) motivaron un cambio en las intervenciones sociales. En esa coyuntura, Duhalde lanzó el Programa Jefes y Jefas de Hogar Desocupados (PJJHD) que consistía en un pago mensual de 150 pesos, que equivalía a 50 dólares según la cotización de la moneda norteamericana en aquella época, a todas las familias desempleadas con hijos a cargo (menores de 18 años o con discapacidad). Ello permitió de algún modo amortiguar la protesta social.

En materia de bienestar el Estado argentino se caracterizó por impulsar un «sistema dual» que articuló «lo productivo/empleable» (término que refiere a la promoción de políticas de empleo) con lo «asistencial/ inempleable», esto es, programas sociales dirigidos a sectores vulnerables (Pautassi et al., 2013).

Salvia et al. (2015), siguiendo a Moreno y Serrano Pascual $(2007)^{7}$, advierte que los Programas Sociales pueden agruparse en dos tipos: Programas Tipo Workfare ${ }^{8}$ y Programas Tipo Welfare ${ }^{9}$. Si bien en común ambos tienen por objetivo transferir ingresos a poblaciones vulnerables con el fin de reducir riesgos económicos, se diferencian en que mientras los primeros exigen a cambio de esa provisión una contraprestación laboral de entrenamiento y búsqueda de empleo, los segundos no sólo no conllevan tal imposición sino que además el suministro a familias excluidas del mercado de trabajo formal y, por tanto, del sistema de seguridad social, puede ser de diverso tipo: ingresos, alimentos, bienes o servicios, etc.

La clasificación antes expuesta sugiere que la AUHPS se enmarca en la lógica de los programas del tipo welfare en la medida en que el Estado (como responsable de proveer un mínimo de subsistencia a las poblaciones en riesgo) asume un rol tutelar mediante la transferencia mensual de ingresos a aquellas familias desempleadas o con empleo informal a quienes le impone condicionalidades de cuyo cumplimiento depende la continuidad de la percepción.

Dicho lo anterior, cabe aclarar que de ninguna manera esta política constituye un plan social como suele concebirse erróneamente en el imaginario colectivo (Vargas, 2018). En el próximo apartado al analizar la AUHPS se ahondará en la razón que motiva tal afirmación.

\section{LA AUHPS EN ARGENTINA: SURGIMIENTO Y MARCO NORMATIVO}

La creación de trabajo, en tanto empleo formal, fue el eje central del modelo impulsado por el Kirchnerismo. Muchos de los cursos de acción trazados por esa gestión gubernamental apuntaron con éxito en tal dirección. Las evidencias señalan que entre los años 2003-2009 se produjo un descenso paulatino tanto del desempleo como de la informalidad laboral.

\footnotetext{
7 Para profundizar en esta línea ver el artículo titulado "Europeización del Bienestar y activación".

8 Se adoptaron como sistema de protección al desempleo. Ejemplos de este tipo de Programas Sociales son: Programa Trabajar, Integración Comunitaria, Desarrollo Local, Manos a la Obra, Proyecto Joven, entre otros. También se incluye en esta categoría el Programa Jefes y Jefas de Hogar Desocupados (PJDHD) cuya cobertura alcanzó a 2 millones de personas (SALVIA et al., 2015).

9 Estos Programas responden a un cambio de paradigma en materia de política social. El ejemplo paradigmático lo constituyen las Políticas de Transferencias Condicionadas de Ingreso que se implementaron a partir del año 2009: AUH, AUE, PROGRESAR, etc.
} 
Tal como referencia Agis et al. (2013) en el periodo arriba consignado se registró un crecimiento anual medio del empleo urbano total de $2,6 \%$ en tanto que la Población Económicamente Activa (PEA) se incrementó al 1,2\% anual medio, hecho que posibilitó la caída del desempleo. Asimismo, el trabajo no registrado experimentó una disminución de $-27 \%$.

En ese escenario, el trabajo aparecía no sólo como la vía privilegiada para el logro del bienestar sino como la única política universalizable (Arcidiácono, 2016).

Empero el año 2009 fue turbulento en tanto aún perduraban las consecuencias que la crisis internacional del año anterior ${ }^{10}$, por efectos de la globalización, produjo en la estructura económica del país, atentando contra la principal política del kirchnerismo: la creación de trabajo genuino (Vargas, 2018).

Esa coyuntura derivó en la imposibilidad del mercado de trabajo formal de absorber mano de obra desocupada con la regularidad que caracterizó a los años antes reseñados. Ante ello, surgió la necesidad de implementar una política social que contenga tanto a las familias de los trabajadores que se desempeñaban en la informalidad laboral como así también a las de aquellos que se encontraban circunstancialmente desocupados.

La estrategia, sustentada en una mirada keynesiana, fue «inyectar» dinero en la economía para reactivar el consumo y la inversión, lo que consecuentemente, como efecto multiplicador, redundaría en la creación de nuevas fuentes de empleo.

En razón de ello, el 29 de octubre del año 2009 surge la "Asignación Universal por Hijo para la Protección Social" (AUHPS), una política de transferencia condicionada de ingresos instaurada por la entonces presidenta (2007-2015) Cristina Fernández de Kirchner, a través del Decreto de Necesidad y Urgencia (DNU) N. ${ }^{\circ} 1602 / 09^{11}$.

Ese hecho trascendental en materia de política social inaugura una nueva etapa en el sistema de protección social argentino (Arcidiácono et al., 2011) (Pautassi et al., 2013).

Como justificativo de esa creación, en forma adicional y complementaria a la lectura de coyuntural señalada al inicio de este apartado, el gobierno añadió una explicación de tipo estructural que aludía a la desprotección ex profeso del Estado durante la hegemonía neoliberal de los años noventa, época en la que se perjudicó abruptamente las trayectorias laborales de los trabajadores. Bajo esta óptica, la AUHPS se presentaba como una política reparadora de la acción u omisión del Estado en el período aludido.

Ahora bien ¿En qué consiste la referida política? ¿Cuáles fueron sus fundamentos? ¿Quiénes son sus destinatarios? ¿Qué requisitos y qué condicionalidades se deben cumplir para acceder a ella? Son algunos de los interrogantes que arrojarán luz sobre el más importante PTCl de Argentina en términos de extensión de derechos, cobertura e impactos.

La AUHPS consiste en un estipendio mensual instituido en el marco de un subsistema no contributivo de seguridad social. En efecto, el DNU que ordenó su creación amplió la cobertura del sistema de asignaciones familiares contemplado en la Ley Nacional N. ${ }^{\circ} 24.714$ incorporando a ese texto como inciso c): «Un subsistema no contributivo de Asignación Universal por Hijo para la Protección Social destinado a niños, niñas y adolescentes residentes en la República Argentina, que no tengan otra asignación familiar prevista por la presente ley y pertenezcan a grupos familiares que se encuentren desocupados o se desempeñen en la economía informal».

Esa cualidad la distingue de la mayoría de los PTCI latinoamericanos. Aunque comparte con éstos ser una prestación monetaria diseñada con el fin de invertir en capital humano de niños, niñas y adolescentes hasta los 18 años de edad (o sin límite etario cuando se trate de una persona con discapacidad), siempre que sus padres, madres, tutores o curadores estén insertos en un sistema de informalidad laboral o se encuentren transitoriamente desempleados. Posteriormente, la Administración Nacional de la Seguridad Social (ANSES), mediante Resolución N. ${ }^{\circ} 393 / 09$, extendió ese derecho a hijos e hijas de monotributistas sociales (art. 2) y de trabajadores del servicio doméstico (art. 3), aclarando que en ambos casos los adultos no deben percibir ingresos que superen el monto fijado como salario mínimo, vital y móvil.

Lo anterior da cuenta de que la política bajo análisis sigue los lineamientos de focalización en una población específica como la mayoría de los programas de transferencias condicionadas de ingreso de la región.

10 Se trata de la crisis económica mundial más importante desde aquella que acaeció en 1929. El detonante si bien se originó en el mercado de hipotecas inmobiliarias en los EE.UU, su alcance se extendió al sistema financiero global y derivó finalmente en una crisis global del empleo a medida que las restricciones crediticias afectaron a la economía real y los flujos de comercio internacional colapsaban (Ministerio de Trabajo, Empleo y Seguridad Social, y Oficina de País de la OIT para la Argentina, 2012).

11 Esa vía de instrumentación fue cuestionada porque si bien los DNU tienen «fuerza de ley» se privó a la política del respaldo político que otorgan los procesos deliberativos (DANANI, 2013). 
Sin embargo, siguiendo la lectura de Mazzola (2015) en el caso puntual de la AUHPS es pertinente hablar de lo que ella denomina «universalismo a través de la selectividad» porque si bien se focaliza en una población objetivo determinada, la finalidad última es universalizar un derecho que existía con anterioridad sólo para un grupo determinado de trabajadores (los que poseían empleo registrado).

Se trata de una «universalidad ponderada» o "restringida», es decir, vinculada a la extensión de la población trabajadora cubierta y no sobre la base del criterio de ciudadanía sobre el que se sostienen las políticas tradicionalmente universales en la Argentina (Hintze, 2015: 59).

Dicho esto, conviene aclarar que AUHPS no constituye un «plan social», como usualmente se cree, en tanto quiebra la lógica asistencial y clientelar en los que se inscriben aquellos (Vargas, 2018). A través de esta intervención social «se superan mecanismos que otorgan márgenes de designación discrecional, que asignan recursos según afinidades políticas, favoritismos y/o poblaciones con mayor poder de presión» (Ambort, 2014: 185).

La centralidad en la AUHPS es romper con la exclusividad de la lógica contributiva inherente al sistema de asignaciones familiares, vigente desde el año 1957, a fin de extenderlo a trabajadores no contemplados en él.

En ese esquema el derecho a la percepción de asignaciones se encontraba condicionado y legitimado por la relación de los sujetos con el mercado laboral -formalizada legalmente- y los aportes financieros de empleadores, trabajadores y del propio Estado al sistema de seguridad social (Pautassi et al., 2013).

La AUHPS invierte esa lógica a fin de configurar un sistema protectorio que reconozca a trabajadores que, en razón de su desempeño en la economía informal, estaban marginados de las asignaciones familiares. Con esa finalidad circunscribe a éstos a la lógica interna de funcionamiento del sistema de seguridad social que opera bajo el principio de solidaridad e implica la sujeción de la situación individual al bien común (Vargas, 2018).

Históricamente tanto esos trabajadores como los que se encontraban circunstancialmente desempleados fueron víctimas de injusticia de un sistema que no sólo los excluyó sino que estableció, como única alternativa en los años precedentes, políticas de corte asistencial con focalización en la pobreza y comprobación de medios (Danani, 2013).

En relación a las especificidades de la prestación, según se desprende del instrumento jurídico de creación, la AUHPS es incompatible con las que contempla la Ley N. ${ }^{\circ} 24.714$ y con otras de carácter contributivo o no ya sean del ámbito provincial, municipal o provengan de la Ciudad Autónoma de Buenos Aires.

Por otra parte, el DNU establece un tope de cinco hijos por cada núcleo familiar. Dicha limitación resulta deliberadamente restrictiva para el sexto hijo/a; que queda en un espacio de injustificada ausencia de cobertura. Mientras los hogares de 7 hijos se encuentran resguardados por la pensión no contributiva dispuesta a tal fin, aquellos no pueden encuadrarse en ninguna de esas dos opciones (Lo Vuolo, 2009).

No hay argumentos oficiales sobre los criterios que guiaron tal decisión. No obstante, en la academia hay autores que hipotetizan que:

Esta limitación puede estar relacionada con los temores -ya existentes en los orígenes del PJJHD- de crear un efecto distorsionante en el mercado de trabajo que supuestamente podría presentarse al ir incrementándose los ingresos de los hogares a través de la multiplicación de las asignaciones familiares, y, como consecuencia, pudiendo sus integrantes prescindir de la venta de su fuerza de trabajo. En este sentido, el límite de hijos podría estar ligado con la intención de no superar el valor de la Canasta Básica Alimentaria a través de los montos de la AUH por cada hijo, o incluso relacionado con un posible temor pronatalista (Pautassi et al., 2013: 26).

En los considerandos del DNU N. ${ }^{\circ} 1602 / 09$ se destaca que «la clave para una solución estructural del tema de la pobreza sigue afincada en el crecimiento económico y la creación constante de puestos de trabajo. El trabajo decente sigue siendo el elemento cohesionante de la familia y de la sociedad, que permite el desarrollo de la persona».

Asimismo, si bien se reconoce que la puesta en marcha de la AUHPS no garantizará por sí sola el fin de la pobreza, se advierte que esa intervención resultará «un paliativo importante», esto es, «una respuesta reparadora ${ }^{12}$ a una población que ha sido duramente castigada por políticas económicas de corte neoliberal».

12 Esta idea fue remarcada por la entonces presidenta Cristina Fernández de Kirchner (2009) en el discurso esgrimido en ocasión del acto de lanzamiento de la AUHPS cuando, luego de expresar satisfacción por esta intervención social destinada a los menores 
Precisamente las políticas de los años noventa se caracterizaron por no incluir en su propia naturaleza la equidad como condición. En aquella época, la abrupta caída del trabajo registrado tuvo un efecto devastador en sectores populares y medios en tanto originó la pérdida de derechos inherentes a la seguridad social, dejando a una proporción muy importante de trabajadores y a sus hijos e hijas sin acceso a asignaciones familiares. Estos últimos, al constituir la población más vulnerable, fueron las principales víctimas de las secuelas provocadas por el modelo neoliberal (Roca et al., 2012).

La AUHPS establece una serie de requisitos «ex ante» (indispensables para acceder al beneficio) y «ex post» (de cuyo cumplimiento depende su continuidad). En la literatura existente en la materia también se identifica a este último elemento como «condicionalidades» o «corresponsabilidades».

En materia de requisitos ex ante se exige que el niño, niña o adolescente sea argentino, hijo de argentino nativo o por opción, naturalizado o con residencia legal en el país por un periodo no inferior a 3 años. Mediante declaración jurada ${ }^{13}$ se debe acreditar fehacientemente la identidad y el vínculo que une al menor con el adulto (padre, madre, tutor, curador).

Los requisitos ex post se encuentran vinculados a la demostración de prácticas asociadas a los ámbitos educativo y sanitario. Según documenta el Observatorio de la Seguridad Social (2012) la meta a largo plazo es consolidar el vínculo de familias de menores recursos con la educación y la salud infantil.

Con esa finalidad la Resolución de ANSES N. 132/2010 implementó la "Libreta Nacional de la Seguridad Social, Salud y Educación" ${ }^{14}$. Un documento único y personal de los niños, niñas y adolescentes que perciben la AUHPS en el que se consigna información fidedigna sobre dichas prácticas: inserción en el sistema educativo formal (la autoridad escolar debía certificar la condición de alumno regular) y controles sanitarios desde los 6 hasta los 18 años, lo que implica además el cumplimiento de la inmunización obligatoria exigida en el calendario nacional de vacunación. A los menores de 6 años además de ello se les exigía la inscripción en el Plan Nacer ${ }^{15}$.

El Plan Nacer tenía por objeto reducir la mortalidad y morbilidad materna e infantil asociadas a problemas en el acceso a servicios de atención médica especializada. A tal fin brindaba cobertura de salud a mujeres embarazadas hasta los 45 días posteriores al parto y a niños y niñas menores de 6 años sin obra social. Las prestaciones contemplaban una variedad de controles clínicos (mamario, peso, medición, latidos del bebé y papanicolau), consejos sobre promoción de lactancia, pautas de alimentación y crianza, prevención de accidentes, intoxicaciones, muerte súbita, etc., oftalmología, odontología, análisis de sangre y orina, grupo sanguíneo, sida, chagas, sífilis, vacunas y, en caso de ser necesario, derivación a: médicos especialistas, nutricionistas, trabajadores sociales, psicólogos, etc. En el año 2012, 7.023 establecimientos de salud de todo el país participaban de ese plan sanitario (Observatorio de la Seguridad Social, 2012).

Para corroborar el cumplimiento de los requisitos exigidos por la AUHPS se dispuso que los beneficiarios recibirían mensualmente el $80 \%$ del monto total de la asignación y el $20 \%$ restante se retendría en una caja de ahorro a nombre del titular en el Banco de la Nación Argentina hasta que se acrediten (dos veces al año) los controles sanitarios correspondientes y la certificación de cumplimiento del ciclo escolar.

La dificultad que presenta esa exigencia es que en contextos inflacionarios la retención del $20 \%$ se traduce de inmediato en una pérdida del poder adquisitivo (Arcidiácono, 2016) (Arcidiácono, 2017).

No obstante, cabe advertir que la aplicación de condicionalidades pretende lograr una mayor integración social mediante el acceso a diferentes derechos sociales (Garcés y Estévez, 2012).

de 18 años, señaló que la política constituye «un acto de estricta reparación, de justicia va a ser cuando su padre tenga un buen trabajo, un buen salario y una buena casa». Discurso disponible en: https://www.cfkargentina.com/palabras-de-cristina-fernandez-de-kirchneranunciando-la-asignacion-universal-por-hijo/.

13 No existen fechas límites para materializar la inscripción, por tanto todo trabajador con hijos a cargo cuya trayectoria laboral se vea interrumpida o transcurra en la informalidad laboral y cumpla con los requisitos exigidos, puede acceder a ella.

14 Ese instrumento con posterioridad fue reemplazado por el "Formulario Libreta PS. 1.47" que se encontraba digitalizado, lo que facilitaba su descarga a través de la página web de ANSES. El procedimiento era igual al anterior, en tanto debía completarse y firmarse por las autoridades escolares y sanitarias correspondientes y luego presentarse ante el órgano rector de la seguridad social.

15 El instrumento normativo que prevé la implementación de esta intervención social es la Resolución N. ${ }^{\circ} 198 / 2003$ que crea en el artículo 1 el "Programa para la Creación de Seguros de Maternidad e Infancia Provinciales". No obstante, el Plan Nacer comenzó a implementarse en el año 2004 en las provincias del Noroeste (Jujuy, Salta, Tucumán, Catamarca y Santiago del Estero) y Noreste (Chaco, Misiones, Formosa y Corrientes), en razón de los preocupantes indicadores de salud infantil, cobertura de la seguridad social y pobreza. Luego, a partir del año 2007, se extendió al resto de las regiones del país. A partir del año 2012, el Plan Nacer fue reemplazado por el Programa SUMAR que no sólo brinda cobertura a la misma población objetivo contenida en aquél (embarazadas y niños y niñas hasta 5 años) sino también a niños/as y adolescentes de 6 a 19 años y a mujeres y hombres hasta los 64 años. 
Por ello, los requisitos ex post se encuentran estrechamente relacionados con la meta de largo plazo de erradicar la pobreza gestando las condiciones que les permita a los sujetos destinatarios una movilidad social ascendente $y$, consecuentemente, mejores posibilidades de inserción a futuro.

De acuerdo con lo anterior, «A través de este mecanismo, se pretende que la población receptora adquiera las credenciales educativas y la condición de salud que le permita interrumpir el circulo de reproducción intergeneracional de la pobreza» (Kliksberg y Novacovsky, 2015: 50).

Kliksberg y Novacovsky (2015) en lugar del término condicionalidades prefieren usar la expresión "corresponsabilidades» bajo el argumento de que las exigencias en materia de salud y educación obligan en partes iguales tanto a los receptores como al propio Estado. En el caso de los primeros (padres, madres, tutores o curadores) deben acreditar el cumplimiento de las exigencias educativas y sanitarias. Como contracara de esa obligación, el Estado queda comprometido a invertir en esos campos no sólo en materia de infraestructura sino también en profesionales y en la tecnología adecuada para garantizar el pleno acceso a estos derechos.

«Los gobiernos deben tener claro que están incentivando una demanda de servicios públicos, por lo que la implementación de estos programas debe estar acompañada de una fuerte inversión social en infraestructura y recurso humano para proveer servicios de salud y educación» (Kliksberg y Novacovsky, 2015: 57).

La obligatoriedad de inversión social permite superar la fragmentación en materia de política social e instaurar un nuevo paradigma que busca articular las intervenciones sociales del Estado. En este marco, iniciativas como la AUHPS «desnudan el déficit oculto y las problemáticas de exclusión de los servicios de salud y educación redundando en una mejora de éstos» (Kliksberg y Novacovsky, 2015: 57).

La AUHPS se financia con recursos del sistema de Seguridad Social: aportes, contribuciones, impuestos, intereses, rentas y transferencias del Tesoro; y los rendimientos anuales del Fondo de Garantía de Sustentabilidad del Régimen Previsional Público de Reparto ${ }^{16}$ (Lo Vuolo, 2010).

En sus orígenes la actualización de montos de la AUHPS estuvo atada a la discrecionalidad en tanto dependía, en forma exclusiva, de una decisión política. A partir de la sanción de la Ley N. ${ }^{\circ} 27.160^{17}$ se estipula que las asignaciones previstas en la Ley N. ${ }^{\circ} 24.714$ de Asignaciones Familiares, complementarias y modificatorias (esto incluye la AUHPS) serán móviles y de carácter semestral con excepción de la asignación por maternidad ${ }^{18}$.

Como complemento de la política analizada, el gobierno estableció otros dos tipos de intervenciones sociales: la Asignación Universal por Embarazo para la Protección Social (AUEPS) y la Asignación por Ayuda Escolar (AAE).

La AUEPS se crea en el año 2011 mediante el Decreto de Necesidad y Urgencia N. ${ }^{\circ}$ 446/2011 con el fin de disminuir los índices de mortalidad maternal, perinatal, neonatal e infantil que se encuentran asociados a problemas en el acceso a servicios de salud. Se trata de una prestación monetaria no retributiva de carácter mensual para toda embarazada (siempre que ella o su cónyuge se encuentren desempleados o se desempeñen bajo un régimen de informalidad laboral) desde la décimo segunda semana de gestación hasta el nacimiento o interrupción del embarazo. Esta política le exige a la mujer como contraprestación la inscripción en el "Plan Nacer" y la realización de chequeos acordes a las etapas del embarazo.

La AAE, creada mediante Decreto de Necesidad y Urgencia N. ${ }^{\circ} 504 / 2015$, extiende a los trabajadores informales y a los transitoriamente desocupados con hijos en edad escolar, el monto por escolaridad que prevé la Ley N. ${ }^{\circ} 24.714$ para trabajadores formales, equiparando en el derecho a esta percepción a los titulares de Asignaciones Familiares con los de la AUHPS.

16 El Fondo de Garantía de Sustentabilidad (FGS) fue creado por Decreto N. ${ }^{\circ} 897 / 07$ con la finalidad de: a) Atenuar el impacto financiero que sobre el régimen previsional público pudiera ejercer la evolución negativa de variables económicas y sociales. b) Constituirse como fondo de reserva a fin de instrumentar una adecuada inversión de los excedentes financieros del régimen previsional público garantizando el carácter previsional de los mismos. c) Contribuir a la preservación del valor y/o rentabilidad de los recursos del Fondo. d) Atender eventuales insuficiencias en el financiamiento del régimen previsional público a efectos de preservar la cuantía de las prestaciones previsionales (Art. 1).

17 Esta legislación fue producto de la iniciativa del Poder Ejecutivo. El proyecto fue enviado por la entonces Presidenta Cristina Fernández de Kirchner en junio de 2015 para que sea discutido en el Congreso de la Nación. Éste, después de un extenso debate en las dos cámaras, le da sanción definitiva el 15 de julio de ese año. Dos días después de esa fecha fue promulgada y publicada en el Boletín Oficial.

18 Para realizar el cálculo de la movilidad se utiliza el mismo índice empleado para las prestaciones del régimen previsional público que figura en el anexo de la Ley N. ${ }^{\circ} 26.417$. 
Estas tres intervenciones (AUHPS, AUEPS y AAE) constituyen un avance significativo en materia de política social, en la medida en que brindaron cobertura a grupos que históricamente habían permanecido invisibilizados y excluidos de los mecanismos de la seguridad social.

Siguiendo a Lo Vuolo (2009), conviene subrayar que el reconocimiento de los trabajadores informales y de los desempleados como «categoría en sí» a ser protegida constituye la característica más novedosa de este tipo de políticas aplicadas en el país.

\section{LOS NIÑOS, NIÑAS Y ADOLESCENTES COMO SUJETOS DE DERECHO DE LA AUHPS}

Roxana Mazzola (2015) indica que los inicios del siglo XXI están marcados por el paradigma de «protección ampliada de la infancia». Se trata de un nuevo enfoque en gestación que según la autora se caracteriza por:

1. Cercanía al enfoque de derechos consagrado en la "Convención Internacional de los Derechos del Niño" que concibe a la cuestión social de la infancia como una problemática derivada de la falta de garantías y promoción de sus derechos.

2. Recuperación del rol de la nación como nivelador de inequidades en un país federal, lo que implica mayor presencia estatal y acciones distributivas a favor de los territorios más postergados.

3. Ampliación de la concepción de seguridad social a partir de la extensión de prestaciones que históricamente fueron sectoriales en tanto estuvieron atadas a la condición de trabajador registrado.

4. Impacto en el papel de las provincias: interpelación y fortalecimiento de las capacidades estatales subnacionales en salud, educación y desarrollo social.

5. Alejamiento de la interpretación restrictiva y gerencialista de la focalización y descentralización.

6. Nuevas reglas de juego e institucionalidad en creación: sanción de la Ley N. 26.061 "De Protección Integral de los Derechos de los Niños, Niñas y Adolescentes" y derogación de la Ley de Patronato de 1919.

7. Nuevas legislaciones que apuntalan el sentido nuevo de la institucionalidad en creación: Ley N. ${ }^{\circ} 25.673$ "Programa Nacional de Salud Sexual y Procreación Responsable", Ley N. ${ }^{\circ} 26.075$ "Incremento de Inversión en Educación", Ley N. ${ }^{\circ} 26.206$ "De Educación Nacional", y su modificatoria Ley N..$^{\circ} 27.045$ por la que se declara la obligatoriedad de la educación inicial a partir de los cuatro años, Ley N. ${ }^{\circ} 26.390$ "Prohibición del Trabajo Infantil y Protección del Trabajo Adolescente", entre otras.

8. Articulación y fortalecimiento de las políticas públicas de la infancia: creación del Plan Nacer (2004), implementación del Programa Conectar Igualdad, ampliación del Calendario Nacional de Vacunación (éste pasó de 6 a 19 vacunas gratuitas y obligatorias en el periodo 2003-2014), etc.

Dicho lo anterior, al analizar la AUHPS se infiere que es una política pensada en el niño, niña o adolescente como sujeto de derecho en consonancia con el espíritu de la Ley $\mathrm{N} .{ }^{\circ} 26.061^{19}$. Los considerandos del DNU 1602/2009 explicitan la correspondencia de la iniciativa con esa legislación protectoria.

El texto normativo precedentemente citado tiene como uno de sus principios rectores «el interés superior del niño», según el cual todos aquellos que residan en el territorio argentino tienen derecho a gozar de la máxima satisfacción integral y simultánea de los derechos y garantías reconocidos por la legislación, entre los que se incluyen: el derecho a una buena calidad de vida, a la educación, a la salud, a la dignidad, a los beneficios de la seguridad social, entre otros.

El concepto de «interés superior» enunciado en el artículo $3 .^{\circ}$ de la Ley N.${ }^{\circ} 26.061$ presupone que ante un eventual conflicto entre los derechos e intereses de los niños, niñas y adolescentes frente a otros derechos e intereses igualmente legítimos, prevalecerán los primeros. Dicho de otra manera, la protección de la infancia se erige como paradigma rector.

Por ello, en observancia del artículo $26 .^{\circ}$ de ese marco normativo, el Estado asume la obligación impuesta de diseñar e implementar políticas y programas de inclusión para niños, niñas y adolescentes, que tengan presente tanto los recursos como la situación de éstos y de las personas que sean responsables de su mantenimiento (padres, madres, tutores).

19 Ley de Protección Integral de los Derechos de Niños, Niñas y Adolescentes. Sancionada por el Congreso de la Nación Argentina el 28 de septiembre de 2005. 
En este marco, Arza y Chahbenderian (2014) señalan que la AUHPS permitió la consolidación de un esquema sui generis de tres beneficios que dependían de la situación laboral y de los ingresos de los padres, madres o tutores: 1) asignación no contributiva para los hijos e hijas de trabajadores informales, desempleados, monotributistas sociales o personal del servicio doméstico cuyos ingresos sean inferiores al salario mínimo, vital y móvil, 2) asignaciones contributivas para hijos e hijas de trabajadores registrados de ingresos medios-bajos y 3) deducciones fiscales al impuesto a las ganancias para los trabajadores que, en función de sus ingresos, están alanzados por ese tributo, siempre que éstos tengan a cargo a menores de 18 años.

De este modo, la AUHPS es una política social diseñada sobre la base de la ampliación de derechos e implica el reconocimiento de un derecho social: el derecho de los niños, niñas y adolescentes argentinos no sólo a estar incluidos sino también a gozar de un estándar básico de vida, bienestar y seguridad económica. Al mismo tiempo, esta política ratifica la universalidad de los derechos sociales hacia aquellos que, aun participando del mercado de trabajo, se encontraban impedidos de recibir los beneficios de las asignaciones familiares por su situación de informalidad (Observatorio de la Seguridad Social, 2012).

En sus orígenes la asignación universal cubrió a 3,3 millones de niños y jóvenes en situación de vulnerabilidad social. No obstante, ese número inicial fue variando a lo largo de tiempo ${ }^{20}$. En mayo de 2010 ascendió a casi 3,7 millones, mientras que en diciembre de 2011 se registró un leve descenso: 3,5 millones ${ }^{21}$. Respecto de las personas con discapacidad ${ }^{22}$, para los cuales la prestación no establece límite de edad, se cubrió en ese mismo año a 20.457 beneficiarios (Observatorio de la Seguridad Social, 2012).

Tomando como referencia los datos de diciembre de 2011, la distribución por sexo marcaba que el $49,2 \%$ de los beneficiarios eran niñas y $50,8 \%$ niños. En el mismo periodo, la mayor cantidad de beneficiarios se concentraba en el rango de los primeros años de vida: 888.332 eran menores de 4 años (en términos porcentuales ello representaba un $25,3 \%$ del total). La edad modal se ubicaba en los 2 años (Observatorio de la Seguridad Social, 2012).

Al comparar la edad de los beneficiaros con el ciclo educativo en el que éstos estaban insertos, el Observatorio de la Seguridad Social produjo la siguiente información.

\section{GRÁFICO 1. BENEFICIARIOS SEgúN EDAD Y ETAPA EDUCATIVA CORRESPONDIENTE}

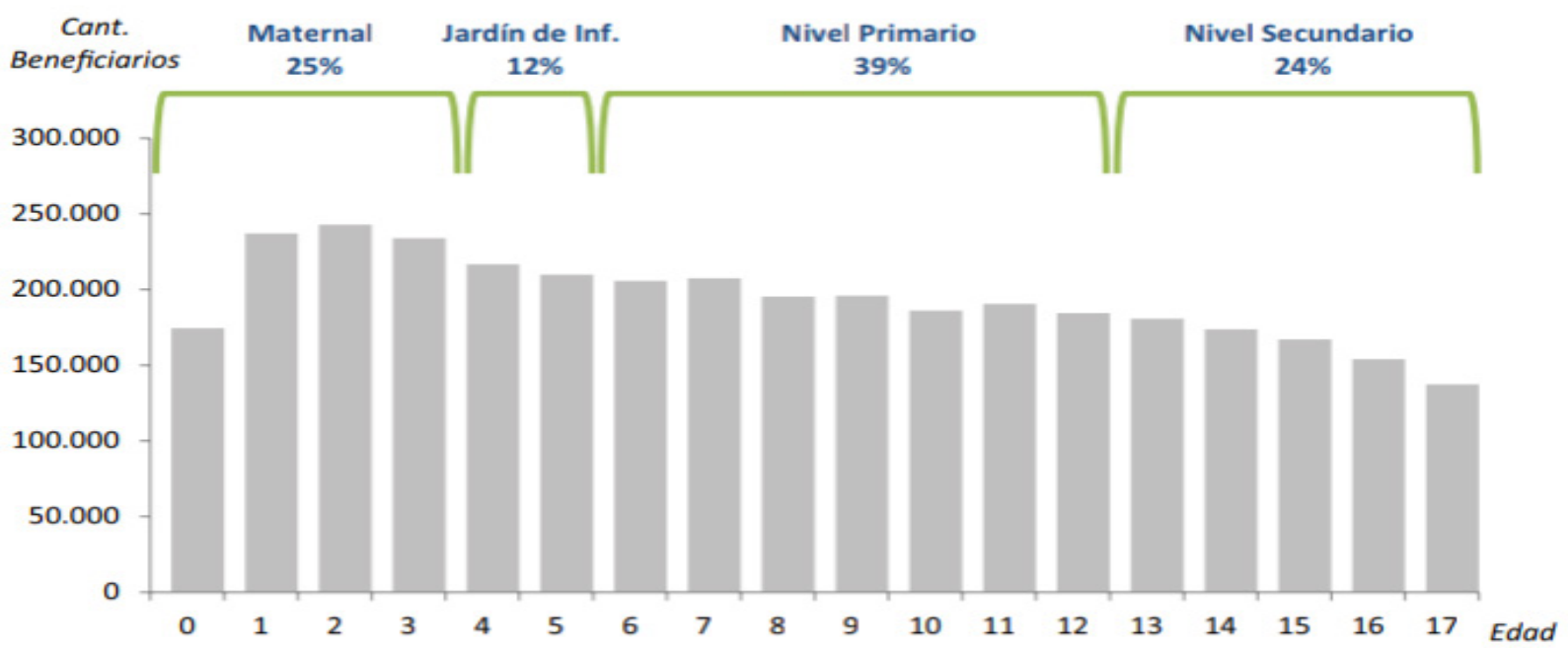

Fuente: Observatorio de la Seguridad Social (2012).

20 Desde diciembre de 2015 con la llegada de cambiemos al gobierno, se incorporó a los hijos de monotributistas, pero también hubo una caída abrupta del empleo, por lo que el número de beneficiarios se incrementó significativamente. No obstante, ello escapa al objeto del presente trabajo que, como su título lo indica, pretende concentrarse en los orígenes de la AUHPS, razón por la cual en este punto se toman datos producidos por el Observatorio de la Seguridad Social hasta diciembre del año 2011.

21 En relación a la situación laboral de los padres, madres y tutores de los beneficiarios receptores de la AUHPS, el Observatorio de la Seguridad Social (2012) documenta que a diciembre de 2011 el 94,0\% se encontraba desempleado o trabajando en condiciones no registradas, el 3,9\% estaban inscriptos como monotributistas sociales y el 2,1\% trabajan en empleo doméstico registrado.

22 Según documenta el Observatorio de la Seguridad Social (2012) en términos relativos ese subgrupo representa en forma sostenida entre un $0,2 \%$ y un $0,6 \%$ del total. 
Según puede observarse en el grafico precedente, a diciembre de 2011 el mayor número de beneficiarios se concentraba en el nivel primario, el segundo en maternal (educación no obligatoria) y el tercero en nivel secundario, en tanto que el menor número correspondía a niños y niñas en nivel inicial (jardín de infantes).

Respecto de la distribución territorial, según puede observarse en el cuadro que se presenta a continuación, las provincias con mayor densidad de población (Buenos Aires, Córdoba y Santa Fe) registraban la mayor cantidad de asignaciones. Asimismo, territorios con un núcleo persistente de pobreza y vulnerabilidad como Chaco, Santiago del Estero y Formosa representan un mayor porcentaje de cobertura sobre la población menor de 18 años: 52,3\%, 49,8\% y 47,6\%, respectivamente (Observatorio de la Seguridad Social, 2012).

CuAdRo 1. Distribución TERRITORIAL DE LOS BENEFICIARIOS (POR PROVINCIA - DICIEMBRE 2011)

\begin{tabular}{|c|c|c|c|}
\hline Provincia & Beneficiarios & Población < 18 años & Cobertura \\
\hline Buenos Aires & 1.218 .294 & 4.803 .833 & $25,4 \%$ \\
\hline CABA & 93.583 & 888.559 & $10,5 \%$ \\
\hline Cotamarca & 37.726 & 113.086 & $33,4 \%$ \\
\hline Chaco & 169.584 & 324.433 & $52,3 \%$ \\
\hline Chubut & 27.186 & 156.522 & $17,4 \%$ \\
\hline Córdoba & 273.289 & 1.017.293 & $26,9 \%$ \\
\hline Corrientes & 131.053 & 305.167 & $42,9 \%$ \\
\hline Entre Ríos & 101.047 & 379.999 & $26,6 \%$ \\
\hline Formosa & 77.651 & 162.995 & $47,6 \%$ \\
\hline Jujuy & 74.570 & 207.004 & $36,0 \%$ \\
\hline La Pampa & 24.315 & 98.059 & $24,8 \%$ \\
\hline La Rioja & 29.747 & 102.576 & $29,0 \%$ \\
\hline Mendoza & 163.673 & 534.623 & $30,6 \%$ \\
\hline Misiones & 146.321 & 338.678 & $43,2 \%$ \\
\hline Neuquén & 43.382 & 169.483 & $25,6 \%$ \\
\hline Río Negro & 49.534 & 196.347 & $25,2 \%$ \\
\hline Salta & 149.863 & 373.372 & $40,1 \%$ \\
\hline San Juan & 72.244 & 209.386 & $34,5 \%$ \\
\hline San Luis & 30.502 & 132.911 & $22,9 \%$ \\
\hline Santa Cruz & 11.218 & 84.228 & $13,3 \%$ \\
\hline Santa Fe & 256.814 & 982.140 & $26,1 \%$ \\
\hline Santiago del Estero & 133.913 & 268.708 & $49,8 \%$ \\
\hline Tierra del Fuego & 4.487 & 39.108 & $11,5 \%$ \\
\hline Tucumán & 159.604 & 445.236 & $35,8 \%$ \\
\hline DEPÓSITO EN CBU & 27.623 & - & - \\
\hline TOTAL & 3.507 .223 & 12.333.747 & $28,4 \%$ \\
\hline
\end{tabular}

Fuente: Observatorio de la Seguridad Social (2012). 
La AUHPS no es una dádiva, es un DERECHO. El fuerte carácter institucional de esa política social, sumado a las campañas publicitarias lanzadas en sus inicios en distintos medios de comunicación, trasmitieron este concepto al punto que los propios sujetos de derecho empezaron a reconocerse como tal. Esta afirmación es respaldada por un estudio realizado por Pautassi et al. (2013) en el que la investigadora aplicó una serie de entrevistas a madres receptoras, quienes indicaron que sus hijos tienen plena conciencia de que perciben un ingreso en su nombre, razón por la cual demandan una serie de elementos personales (ropa, calzado, útiles) argumentando como legitimidad de sus reclamos que se trata es una política pensada en ellos.

\section{LAS CONSIDERACIONES Y DEBATES DEL FEMINISMO SOBRE LA AUHPS}

La Resolución de ANSES N. ${ }^{\circ}$ 393/09 fijó las pautas reglamentarias inherentes al cobro del ingreso mensual de la AUHPS. Ese instrumento estableció que cuando la tenencia del niño, niña, adolescente o persona con discapacidad sea compartida por la madre y el padre, aquella siempre tendrá prioridad en la titularidad de la prestación. Mientras que en los casos de separaciones de hecho o divorcios vinculares recaerá en manos de quien ejerza la tenencia.

A partir de lo normado en ese instrumento "una vasta literatura cuestiona el hecho de que las transferencias se otorguen a las "madres", bajo el argumento de que esto significa una mayor carga para ellas» (Pautassi et al., 2013: 32).

En general quienes se dedican a estudiar los sistemas de protección social coinciden tanto en el reconocimiento del impacto positivo que los PTCI provocan sobre la pobreza al mejorar la situación económica de los destinatarios, como en las limitaciones que presentan en términos de género en razón de los sesgos que reproducen al preservar intacta la tradicional división sexual del trabajo ${ }^{23}$.

La división sexual del trabajo «no sólo diferencia las tareas que hacen hombres o mujeres, además, confiere o quita prestigio a estas tareas y también crea desigualdades en las recompensas económicas que se obtienen» (Varela, 2005: 207).

El no cuestionamiento en las intervenciones sociales de esas desigualdades mantiene su plena vigencia, en otras palabras, la política pública contribuye a reproducirla al interior de los núcleos familiares.

Las políticas de reconocimiento y de redistribución coexisten de manera tensa, fragmentada y contradictoria en el campo estatal. Pues mientras por una parte presenciamos una retórica de ampliación e igualación de los derechos y de ciudadanización de las mujeres, que pone en cuestión qué se considera un derecho, para quién y cómo se determina. Por la otra, a la hora de aplicar políticas sociales para la protección social, las mujeres siguen siendo consideradas en sus lugares tradicionales: como madres-cuidadoras, como vulnerables cuyas necesidades particulares son identificadas con las de sus familias y sus obligaciones con las labores domésticas (Anzorena, 2015: 100).

Siguiendo esta línea argumental se observa que «El hecho de que estos programas sean altamente feminizados, no los transforma ni en políticas para las mujeres ni en intervenciones sensibles a sus intereses» (Rodríguez Enríquez, 2011: 31).

Es por esa razón que la crítica feminista recae en la perpetuación del modelo «hombre/proveedor-mujer/ cuidadora» que reserva para los primeros el espacio de lo público y condena a las últimas a las labores privadas a fin de que se erijan en artífices del destino de otros: sus protegidos.

Con posterioridad a la Resolución de ANSES a la que se aludió al inicio del apartado, se dictó el Decreto N. ${ }^{\circ} 614 / 13^{24}$, que reforzó en los considerandos esa visión anclada en sesgos de género al señalar: «Que la mujer es uno de los pilares fundamentales en el que se apoya la familia y la sociedad, teniendo un rol fundamental en el cuidado de los hijos» y «Que dicha condición la hace esencial al momento de ser la receptora de los recursos otorgados por la Seguridad Social para dar cobertura a los niños, adolescentes y personas con discapacidad».

23 Aquí cabe destacar un trabajo de MAXINE MOLYNEUX (2006) titulado: "Madres al servicio de la nueva agenda de pobreza: el Progresa/Programa Oportunidades en México" (traducción propia), donde la autora da cuenta de los sesgos de género que predominan en materia de política social en esos $\mathrm{PTCl}$, en tanto las madres reciben derechos en función de las necesidades de sus hijos, esto es, para cumplir con sus responsabilidades maternas.

24 Dictado con el objeto es establecer rangos, topes y montos de las Asignaciones Familiares contempladas en la Ley $\mathrm{N} .^{\circ} 24.714$ y un suplemento adicional por única vez. 
La mujer en su rol de madre está asociada a una suerte de altruismo que es menos incompleto que en la figura paterna. De ahí que éstas aparezcan como las mejores gestoras o administradoras operativas de las transferencias (Micha, 2019).

Siguiendo la lectura de Anzorena (2015) con frecuencia la responsabilidad materna es enaltecida en las políticas sociales a través de un discurso que coloca a las madres-pobres en lugar de «heroínas» capaces de afrontar una serie de problemas sociales y políticos debido a su papel en la familia y en la comunidad.

En este marco, la tarea de cuidar la vida y el bienestar de otras personas (niños, niñas, adolescentes, personas con discapacidad, adultos mayores) es un trabajo invisible: no valorado ni remunerado y en muchos casos constituye una doble jornada para aquellas mujeres que simultáneamente desarrollan sus trayectorias laborales ya sea en el mercado formal o informal. Cuestión que no ocurre con los hombres que en el mejor de los casos destinan algunas horas de su tiempo a las tareas del hogar, aunque en familias con una fuerte impronta patriarcal esa dedicación puede llegar a ser nula.

De acuerdo con lo indicado en el párrafo precedente, a diferencia de los hombres, las mujeres invierten una mayor cantidad de tiempo en trabajo de cuidado. Tal afirmación está respaldada por los datos que reveló el Instituto Nacional de Estadísticas y Censos (INDEC), quien en el 3. ${ }^{\circ}$ trimestre del año 2013 por primera vez incluyó un módulo sobre trabajo no remunerado en la Encuesta Anual de Hogares Urbanos, con el propósito de medir como distribuyen el tiempo hombres y mujeres ${ }^{25}$.

La información recabada por ese organismo sirvió de insumo para un documento de trabajo del Equipo Latinoamericano de Justicia y Género (ELA) titulado: "El trabajo de cuidado no remunerado en Argentina: un análisis de la evidencia del módulo de Trabajo no Remunerado", elaborado por Corina Rodríguez Enríquez quien observa que:

i) las mujeres destinan un tiempo sustantivamente mayor que los varones al TNR; ii) las jornadas de TNR de las mujeres se incrementan en la edad central, cuando son cónyuges, cuando hay menores de 6 años en el hogar, cuanto menor es la jornada de trabajo en el mercado laboral, y cuanto peor es el nivel de ingreso del hogar en el que viven; iii) aun cuando las mujeres desocupadas e inactivas destinan mayor cantidad de tiempo al TNR, las mujeres ocupadas destinan un tiempo sustantivo (casi 6 horas diarias), lo que se expresa en jornadas de trabajo total muy prolongadas diariamente, lo que les limita la disponibilidad de tiempo «para sí» (dedicadas al autocuidado, al esparcimiento o la capacitación); iv) la situación ocupacional, el nivel de ingreso, la posición en el hogar, el nivel educativo, la edad, no producen ninguna modificación en la cantidad de tiempo que los varones destinan al TNR; v) la única razón por la cual los varones incrementan moderadamente su dedicación al TNR es ante la presencia de menores de 6 años en el hogar, pero siempre en proporciones sustantivamente menores a las mujeres; vi) la desigualdad en el uso del tiempo y en la intensidad del tiempo dedicado al TNR es una experiencia socio-económicamente estratificada, que se convierte por tanto en un vector reproductor de desigualdades (Rodríguez Enríquez, 2014: 4).

Los datos presentados son concluyentes, si bien las mujeres tienen una mayor carga sobre sus espaldas, las medidas de protección social en general no reconocen esa situación, en tanto sus intervenciones no están dirigidas a modificar o morigerar esas desigualdades. Contrariamente «cuando las políticas se basan en el aprovechamiento del reparto de tareas a partir de la naturalización de la división sexual del trabajo (mujer cuidadora/ varón proveedor) y no hay una intención explícita de modificar las relaciones de género, terminan profundizando las relaciones desiguales de género» (Anzorena, 2015: 115).

A pesar de lo descripto Laura Pautassi et al. (2013) afirma que la mirada académica se tensiona con la de las mujeres receptoras, quienes no visualizan como un problema su preeminencia en la administración de la asignación, sino que valoran positivamente tal disposición en razón del impacto, en términos de autonomía, que implica la percepción de un ingreso propio, aunque éste se destine en su totalidad a sus hijos.

«... Al posicionar a la mujer como proveedora de ingresos, se busca promover la equidad de género, brindando a las receptoras la posibilidad de contar con un ingreso propio, sobre el que tiene poder de decisión, fortaleciendo su autonomía, su autoestima y su posición al interior del hogar» (Kliksberg y Novacovsky 2015: 59).

25 Dos antecedentes de esto - aunque de aplicación territorial acotada- fueron las encuestas del uso del tiempo realizadas en la Ciudad Autónoma de Buenos Aires en el año 2005 y en la Ciudad de Rosario (Provincia de Santa Fe) en el año 2010 (RODRÍGUEZ ENRÍQUEZ, 2014). 
El encuadre que provoca la preeminencia de la madre en los casos de tenencia compartida genera un cierto empoderamiento de las mujeres frente a su situación de pobreza, destacable no sólo por los efectos positivos en términos de autonomía del consumo sino también por la reconfiguración, desde un punto de vista económico, de las relaciones al interior del hogar al reducir la dependencia del «pater familias» en la proveeduría exclusiva al sostén familiar.

Adicionalmente a estas consideraciones, es destacable que ante un eventual cese de convivencia (divorcio o nulidad del matrimonio), la percepción de la AUHPS les confiere a las mujeres la posibilidad de manejar recursos propios para la economía familiar mientras transitan largas batallas judiciales como regularmente sucede cuando se encara un juicio de alimentos o de «responsabilidad parental» ${ }^{26}$, según la denominación que otorga el nuevo Código Civil y Comercial de la Nación.

Una de las implicancias de la responsabilidad parental es que la provisión de recursos económicos para el sostén de hijos e hijas es una responsabilidad compartida, esto significa que hombres y mujeres (en caso de familias heteroparentales) deben contribuir por igual a la mantención de los menores a cargo.

Pese a que la legislación es clara, es usual que ante la disolución del vínculo conyugal se presenten una serie de conflictos en torno a dicha responsabilidad. El principal de los desacuerdos es de tinte económico; hay padres que oponen resistencia a la previsión del sostén de sus hijos, razón que obliga a las madres a recurrir a los juzgados de familia para reclamar por esa vía el incumplimiento.

En lo inherente a este aspecto, a diferencia de las mujeres cuyo ex marido o cónyuge poseen empleo registrado (hecho que facilita descontar de su salario la cuota mensual de manutención) a aquellas cuyas ex parejas poseen trabajos informales o se encuentran circunstancialmente desempleados, le es más difícil reclamar jurídicamente el aporte de recursos para el sostén familiar. Si bien la norma estipula que, en los casos donde el progenitor obligado no pueda hacerse cargo, se puede reclamar la manutención a los ascendientes (abuelos), en sectores populares por desconocimiento de los derechos o por no tener conflictos, hay una menor predisposición a reclamar por esta vía.

Ante ese último escenario descripto, contar con una asignación mensual les permite a las mujeres afrontar económicamente los gastos cotidianos del hogar. De igual modo, la política social produce una suerte de alivio a la economía de familias de tipo monomarental ${ }^{27}$ (donde las madres solteras son las únicas responsables del vínculo filial del menor) sobre todo cuando presentan trayectorias laborales débiles con periodos de fluctuación entre el desempleo y la informalidad laboral.

Lo descripto en este apartado permite afirmar que este tipo de intervenciones sociales presentan una mirada parcial de género en tanto mientras, por un lado, constituyen un gran avance en términos de beneficiar a la mujer en su situación de pobreza al empoderarlas con la administración de los recursos económicos que perciben en nombre de sus hijos e hijas, por otro, tienden a reforzar los roles tradicionales de género.

Lo anterior da cuenta de las nociones restrictivas que la AUHPS presenta en este aspecto, situación en la que no difiere del resto de los PTCl. Al respecto Martínez Franzoni y Voorend (2008) señalan que la limitación común de este tipo de programas es que las valoraciones sobre los efectos que tienen sobre las relaciones de género carecen de una noción multidimensional de la equidad. En este sentido, recuerdan que además de la subordinación de tipo económica al interior del hogar deben tenerse en cuenta otras como la relativa al uso del tiempo. Por ello, proponen desagregar la igualdad de género en más de una dimensión y determinar en qué medida las transferencias condicionadas de ingreso moldean unas y otras.

Urge avanzar en lo que no se ha logrado aún: romper la clásica división sexual del trabajo que consolida las desigualdades socialmente construidas entre hombres y mujeres al perpetuar la noción patriarcal de la mujer como única responsable del cuidado de los miembros del hogar. Es necesario transitar hacia «una redefinición de las políticas públicas que supere la escisión entre el reconocimiento de derechos en el orden legal y la garantía estatal, o la identificación de mujeres = madres = familia y por tanto encargadas de la reproducción de la vida» (Anzorena, 2015: 114-115).

Ahora bien: ¿Es posible superar esta situación? Una amplia literatura en la materia considera que para romper los estereotipos de género que reproducen los $\mathrm{PTCl}$ y reconfigurar las relaciones bajo la premisa de la responsabilidad compartida, el Estado debería impulsar una serie de medidas complementarias vinculadas a las tareas de cuidado. Se exige, por ejemplo, inversión en infraestructura para la creación de diversos

26 Tema tratado en el Título VII del Código Civil y Comercial de la Nación (Artículos 638 a 704).

27 El neologismo monomarental no es una terminología reconocida por la Real Academia Española. Ésta emplea el masculino monoparental para referirse a las familias que están formadas solo por el padre o la madre y los/as hijos/as. Sin embargo, se sostiene aquí el femenino no reconocido para señalar que el lenguaje no debería escapar a los debates de género. 
espacios públicos de cuidado tanto en la primera infancia (salas maternales, jardines de infantes e instituciones de similares características) como durante la niñez y adolescencia (centros multidisciplinares deportivos, artísticos, etc.) que les permita a las madres de los destinatarios cierta autonomía para su autorrealización en el mercado laboral.

La ausencia de un sistema público de cuidado genera desigualdades que atraviesan la categoría ocupacional (Ambort, 2014) Por ello, se requiere una auténtica reestructuración social que facilite la socialización del trabajo de cuidado mediante la provisión de mediaciones adecuadas para ello. Esto demanda una mayor asignación de recursos por parte del Estado u otras agencias organizadas que asuman esa responsabilidad (Molyneux, 2005).

La exhortación feminista desde un ámbito académico es el rediseño de las intervenciones existentes de modo tal que concilien la vida laboral y familiar de las mujeres, lo que implica al mismo tiempo estimular la asunción de responsabilidades compartidas no sólo al interior del hogar sino también entre las familias y el aparato estatal:

La organización del cuidado es un elemento central del propio régimen de acumulación, y que, por lo mismo, su inclusión es imprescindible en todo análisis de política... Se requiere de un esfuerzo creativo, no solo en la elaboración de un diagnóstico complejo, sino fundamentalmente para la imaginación de políticas que contribuyan efectivamente a reconfigurar la economía del cuidado en un sentido más equitativo, en el marco de modelos de desarrollo alternativos para los países del Sur (Rodríguez Enríquez, 2007: 239).

La invitación es discutir el cuidado como una problemática que debe ser resuelta por el Estado «el cuidado aparece así como un problema de política pública, que se separa tanto del terreno estricto de lo privado y de su naturalización como asunto de mujeres» (Rodríguez Enríquez, 2012: 28).

Cada una de las políticas públicas que se adoptan operan en un campo atravesado por las relaciones de género. Cada una de ellas tiene asimismo implicancias más directas o indirectas sobre la organización del cuidado. Reconocer y explicitar estas vinculaciones es un paso necesario tanto para potenciar la repercusión de las políticas como para corregir los sesgos negativos que puedan tener con respecto a la posición de las mujeres y la igualdad de género (Rodríguez Enríquez, 2012: 34).

Como sostiene la autora antes citada: «Una sociedad más justa e igualitaria debe sustentarse en una distribución más equitativa del trabajo total (productivo y de cuidado) y en la puesta en práctica de la responsabilidad social y colectiva en la reproducción de las personas» (Rodríguez Enríquez, 2012: 35).

\section{LA MIRADA PEYORATIVA DE LOS SECTORES CONSERVADORES SOBRE LA AUHPS Y LA DESMITIFICACIÓN DE SUS PREJUICIOS}

A partir del surgimiento de la Asignación Universal por Hijo para la Protección Social se han suscitado una serie de resistencias político-culturales para aceptar políticas de corte distributivo con enfoque de derechos (Danani, 2013).

Las críticas se han materializado, principalmente, a través de sectores identificados con ideologías conservadoras, quienes instalaron sobre las familias que la perciben una mirada sustentada en una fuerte carga peyorativa.

En este sentido, fue habitual escuchar expresiones desafortunadas como: «el gobierno mantiene vagos» «no trabajan porque no quieren» "yo pago mis impuestos y esa plata va a parar a los vagos», etc. Estos discursos se encuentran anclados en lo que se conoce como «rebelión de los contribuyentes» que alude a la objeción u oposición al pago de impuestos en tanto existe un desacuerdo respecto del destino de esa contribución.

Identificado con esa línea argumental, un sector de la población de tipo medio y/o alto se autoproclama el sostén financiero de este tipo de políticas a través del pago de sus impuestos.

Ese argumento falaz se desmorona al analizar la Ley de Presupuesto, en tanto planificación operativa anual, instrumento que en lo inherente a la configuración de «recursos» permite corroborar que uno de los tributos que más ingresos le genera al Estado es el Impuesto al Valor Agregado (IVA). Se trata un gravamen indirecto que recae sobre los consumidores y presenta una alícuota que en Argentina es del $21 \%$. En mate- 
ria impositiva éste se ubica dentro de los considerados «impuestos regresivos» porque si bien el porcentaje es igual para todos, la presión recae mayormente sobre los sectores de menores ingresos.

En este punto es necesario desmitificar aquellos discursos anclados en una retórica ficticia que pretende instalar que las personas pobres no contribuyen al sostenimiento del Estado. Como antítesis de esa afirmación se advierte que los receptores de la AUHPS al no tener capacidad de ahorro destinan todos sus ingresos al consumo y al hacerlo, lejos de ser financiados por los extractos sociales más altos como usualmente se cree, su propio consumo no sólo contribuye al sostenimiento de esa política sino además en forma consecuentemente a la reactivación del circuito económico.

Desde el conservadurismo también se lanzaron miradas peyorativas sobre la AUHPS en términos de resultados. El argumento usualmente esgrimido en ese aspecto es que en la praxis concreta los ingresos no eran usados por las familias con el fin que el gobierno pretendió darle a esa política en el momento de su creación.

Aquí cabe recordar la expresión desafortunada que vertió el entonces Senador y presidente del Comité de la Unión Cívica Radical, Ernesto Sáenz, quien en el año 2010 expresó que: «La Asignación Universal se va por la canaleta del juego y de la droga ${ }^{28}$ ", concepción peyorativa y estigmatizante de la pobreza que asocia de forma directa a las familias vulnerables con la drogadicción y la ilegalidad del juego.

Diversos estudios e investigaciones han centrado sus esfuerzos en derribar estos prejuicios produciendo datos concretos sobre el desenlace que provoca la AUHPS en la población.

Así, una investigación dirigida por Kliksberg y Novacovsky (2015) plasmada en el libro "El gran desafío. Romper la trampa de la Desigualdad desde la infancia" rescata como consecuencia positiva la reactivación de los niveles de consumo de los elementos de la canasta básica.

En línea con lo anterior, se desarrollaron las conclusiones de un grupo de sociólogos, antropólogos y economistas que en el año 2011 encararon una investigación financiada por el Ministerio de Salud Pública en la que señalan que los receptores de la AUHPS reconfiguraron sus decisiones de consumo: anexaron nuevos elementos a la alimentación familiar (carne, lácteos, útiles escolares y remedios), agregaron una comida adicional en su dieta diaria, incorporaron marcas más «prestigiosas» de alimentos, y añadieron productos de higiene y limpieza que permitieron mejorar la salud del hogar. Adicionalmente, rescataron como positivo el acceso a créditos formales e informales, la recuperación de la idea de la «planificación» y la reinserción en los sistemas de salud y educación ${ }^{29}$.

En idéntico sentido se expresa Roxana Mazzola (2015) quien advierte que contra los prejuicios la evidencia indica al menos diez aspectos positivos de la AUHPS, a saber:

1. Incrementó el consumo, la ingesta calórica y la diversificación de alimentos.

2. Permitió la planificación de los consumos familiares esenciales (alimentos, remedios, pago de servicios, compra de útiles escolares, ropa y calzado, etc.) y el acceso a créditos.

3. Aportó al ingreso total familiar.

4. Amplificó el acceso al derecho a la seguridad social en la niñez, incorporando un sesgo más distributivo e inclusivo al sistema de asignaciones familiares.

5. Contribuyó a la reducción de la desigualdad social y territorial, aspecto esencial en un país federal.

6. No generó desincentivos al trabajo.

7. Empoderó a niños y mujeres.

8. Mejoró el acceso a los servicios de salud y a cuidados preventivos en la población materno-infantil.

9. Favoreció la retención y el incremento en las tasas de matrícula y asistencia escolar.

10. Llevó a que los implicados de forma directa (destinatarios, médicos, docentes y funcionarios) y la sociedad en su conjunto valorara positivamente las condicionalidades impuestas en salud y educación.

Por último, en términos de impacto, la AUHPS contribuyó a la reducción de los índices de pobreza e indigencia.

"La política social ha pasado a tener -en la actual etapa de políticas heterodoxas y a diferencia del período neoliberal- un papel activo en la trasferencia de recursos económicos a favor de los sectores medios, pobres e indigentes, siendo esto lo que explicaría la reducción de las tasas de indigencia/pobreza, así como la mejora en la distribución del ingreso» (Salvia et al., 2015: 14).

28 Ver nota de DAVID CUFRÉ. Edición 16 de mayo de 2010. Página 12.

29 Ver nota de TOMAS LUKIN. Edición 29 de Enero de 2012. Suplemento Cash. Página 12 


\section{REFLEXIONES FINALES}

Problemas estructurales como la pobreza o la desigualad han ocupado siempre una parte importante de la agenda política de los gobiernos, de ahí que éstos se han planteado el diseño de intervenciones tendientes a reducir $\mathrm{o}$, al menos, atenuar sus efectos.

En los últimos años, los cursos de acción han sido múltiples y diversos, algunos de éstos (los implementados en la década del noventa) respondieron a paradigmas impuestos desde «afuera» por organismos internacionales de crédito. Otros, como los impulsados por el kirchnerismo, fueron diseñados en función de la propia realidad socio-económica y de las problemáticas complejas e irresueltas que el país arrastraba desde aquélla época.

Como se ha dicho en este escrito, en el año 2009 en una coyuntura crítica marcada por la persistencia de los efectos de la crisis internacional del año anterior que impactó en el mercado laboral argentino, frenando la absorción de mano de obra formal con la regularidad registrada desde los inicios del kirchnerismo, se impulsó la política social más igualitaria de los últimos tiempos: la Asignación Universal por Hijo para la Protección Social. Esa intervención si bien se diseña en función de las características de aquél escenario, trasciende el aspecto coyuntural modificando la concepción del bienestar imperante hasta ese momento.

La AUHPS sigue una cierta línea de focalización, es decir, está centrada en una población objetivo a la que el instrumento jurídico de creación identifica como «sectores de la población que resulta necesario atender», aunque la política está basada en una concepción de derechos atada a la condición de ser niño, niña o adolescente o personas con discapacidad en familias cuyos padres, madres o tutores se desempeñen en la informalidad laboral o se encuentren desempleados.

Lo anterior se corresponde con la esencia de restituir derechos al conjunto social, propia del modelo político instaurado en el año 2003. De este modo, sectores que habían permanecido históricamente excluidos se vieron inmersos en un nuevo sistema protectorio, sustentado en el enfoque de derechos humanos, que hace justicia al revertir completamente las concepciones inscriptas en la lógica asistencial predominante durante la hegemonía neoliberal.

Comparativamente con las políticas de corte asistencial, la AUHPS constituye un salto cualitativo en materia de política social por varias razones:

1. Reivindicó a los grupos históricamente excluidos al equiparar, en el derecho a percibir una remuneración mensual, tanto a los hijos de trabajadores informales como a los de los circunstancialmente desocupados con los hijos de los trabajadores formales, cuando la asignación familiar históricamente configuró un atributo exclusivo de estos últimos.

2. Invirtió en capital humano de los niños, niñas y adolescentes al exigirles controles periódicos de salud y la inserción en el sistema educativo formal.

3. Permitió algo fundamental: que los niños, niñas y adolescentes vuelvan a comer en sus casas, quedando como una anécdota del pasado neoliberal de los noventa la imagen de comedores comunitarios implementados para paliar la situación de pobreza extrema de la época. De este modo, profundizó aquello que las intervenciones sociales que precedieron la AUHPS (PJJDHD o Plan Familias) habían comenzado a realizar: la reconstrucción del tejido social fragmentado por el neoliberalismo.

Si bien la AUHPS no es universal, en la medida en que está focalizada en una población objetivo, tiende a la universalización del sistema porque su implementación en el año 2009 derivó en la cobertura cuasi total de la Población Económicamente Activa (PEA) con hijos e hijas a cargo (a excepción de los monotributistas que se incluyeron en el año $2016^{30}$ )

1. Los hijos e hijas de trabajadores formales que perciben ingresos en concordancia con el salario mínimo, vital y móvil (o superiores siempre y cuando no superen el mínimo establecido para la tributación de ganancias) están protegidos por el régimen de asignaciones familiares estipulado en la Ley N. ${ }^{\circ} 24.714$.

2. Los hijos e hijas de trabajadores formales (cuyos ingresos están muy por encima del salario mínimo, vital y móvil y tributan ganancias) también se encuentran protegidos de manera implícita por el

30 El Decreto de Necesidad y Urgencia N. ${ }^{\circ}$ 593/16 amplió ese derecho para los trabajadores aportantes adheridos al Régimen Simplificado para Pequeños Contribuyentes que revistan en las categorías con ingresos más bajos, quedando expresamente excluidas por esa normativa los que tributan en la categoría «J» o superior. 
Estado en la medida en que a sus padres o madres se les realiza una suerte de deducciones al impuesto cuando tienen a cargo menores de 18 años.

3. Los hijos e hijas de trabajadores informales que perciban un ingreso inferior al salario mínimo, vital y móvil, los de aquellos que circunstancialmente estén desempleados, los de monotributistas sociales y los de trabajadores del servicio doméstico, están protegidos por la AUHPS.

La Encuesta Nacional de Protección y Seguridad Social (ENAPROSS), realizada en el año 2011 por el Ministerio de Trabajo, Empleo y Seguridad Social de la Nación, evidencia que el 74,5\% de los menores de 18 años están cubiertos por algún beneficio social o deducción fiscal: $42,5 \%$ por el sistema de asignaciones familiares, $24,9 \%$ por la asignación universal, $4 \%$ por otros programas sociales y $3,2 \%$ por deducción del impuesto a las ganancias (Ministerio de Trabajo, Empleo y Seguridad Social, 2014).

Independientemente de estas valoraciones positivas, cabe resaltar que el diseño de la AUHPS no contempla una lectura profunda de las problemáticas de género; la política presenta algunos sesgos, en tanto no avanza en romper la tradicional división sexual del trabajo que impone «prototipos» de tareas que se asignan en razón del sexo. Desde la academia se denuncia que la preeminencia de la madre en la responsabilidad de administración del beneficio refuerza esa mirada.

Hecha esa advertencia, no se puede negar que esa disposición tuvo un efecto ambivalente porque generó resultados positivos, aunque parciales, en términos de género. Esta parcialidad surge al ubicar en cierto modo la causa de las desigualdades y de la subordinación de las mujeres en su situación de pobreza. Al sujetar a ello la preeminencia en la administración de esos recursos, el efecto fue la reconfiguración de las relaciones económicas al interior del hogar en tanto la percepción de un ingreso estable les permitió a las mujeres cierta autonomía económica de su cónyuge. Sin embargo, esto al mismo tiempo implicó una mayor carga para ellas y la reproducción de los roles anclados en la división sexual del trabajo.

Una política que en esencia busca equiparar, debería avanzar en dirección a modificar esas estructuras. Como se sostuvo en el apartado dedicado a la discusión sobre esta temática, la inversión en infraestructura destinada a espacios de cuidado sería una alternativa para no sobrecargar a las mujeres.

A pesar de las limitaciones en términos de género, de acuerdo con lo consignado en estas páginas, la Asignación Universal por Hijo para la Protección Social no sólo hizo justicia al reconocer a quienes por largos años permanecieron invisibilizados y desprotegidos en materia de asignaciones familiares sino que a su vez elevó la calidad de vida de éstos mediante el acceso a bienes y servicios. Por tanto, sin dudas, es una herramienta complementaria de la política central del kirchnersimo: erradicar la pobreza a través de la creación de empleo.

Como sostiene Danani (2013: 146) «Intervenciones de un periodo y condiciones de vida conforman una unidad... Es que las políticas sociales, finalmente, hacen sociedad».

\section{REFERENCIAS BIBLIOGRÁFICAS}

AGIS, E., CAÑETE, C. y PANIGO, D. (2013): "El impacto de la Asignación Universal por Hijo en Argentina. Presentación formal de los resultados anticipados en 2010”, en Empleo, Desempleo \& Políticas de Empleo, núm. 15. República de Argentina: Centro de Estudios e Investigaciones Laborales (CEIL) del Consejo Nacional de Investigaciones Científicas y Técnicas (CONICET). Disponible en web: http://www.ceil-conicet.gov.ar/wp-content/ uploads/2013/12/edpe15.pdf.

AMBORT, M. L. (2014): “Asignación Universal por Hijo para la Protección Social: alcances y limitaciones en la garantía de derechos sociales", en Revista Latinoamericana de Derechos Humanos, vol. 25, núm. 2, págs. $169-191$. Disponible en web: https://www.revistas.una.ac.cr/index.php/derechoshumanos/article/view/6158/6141.

ANZORENA, C. C. (2015): “¿Qué implica la protección social para las mujeres? Un análisis feminista de las políticas sociales y de igualdad en la Argentina”, en Oxímora Revista Internacional de Ética y Política, núm. 7, págs. 98118. Disponible en web: https://ri.conicet.gov.ar/bitstream/handle/11336/42622/CONICET_Digital_Nro.0391596ee4ed-4e9a-99f6-cf37519714e3_A.pdf?sequence=2\&isAllowed=y.

ARCIDIÁCONO, P.; CARMONA BARRENECHEA, V.; STRASCHNOY, M. (2011): "La asignación universal por hijo para la protección social: rupturas y continuidades, ¿hacia un esquema universal?”, en Revista Margen, núm. 61. Disponible en web: http://www.margen.org/suscri/margen61/straschnoy.pdf.

ARCIDIÁCONO, P. (2016): "Transferencias de Ingresos a los hogares en Argentina", en Revista de Ciencias Sociales Universidad de Costa Rica, vol. I, núm. 151, págs. 95-109. Disponible en web: https://www.redalyc.org/ pdf/153/15345948007.pdf. DOI: https://doi.org/10.15517/rcs.v1i151.24972.

ARCIDIÁCONO, P. (2017): "Asignación Universal por Hijo. Rupturas y continuidades en el campo de las transferencias de ingresos en Argentina”, en Revista Igualdad, Autonomía Personal y Derechos Sociales, núm. 6, págs. 10-43. 
GAPP. Nueva Época - N. 23, mayo-octubre 2020 - ISSN: 1989-8991 - DOI: 10.24965/gapp.i23.10717 - [Págs. 111-134]

Transferencia Condicionada de Ingresos en Argentina: una mirada hacia los orígenes de la Asignación Universal por Hijo ..

Melisa Cristina Vargas

Ciudad Autónoma de Buenos Aires: Asociación de Derecho Administrativo. Disponible en web: https://ri.conicet. gov.ar/handle/11336/74343.

ARZA, C.; CHAHBENDERIAN, F. (2014): "Programas de transferencias monetarias a las familias: las experiencias de Argentina, Bolivia, Brasil y Chile", en Documentos de Trabajo CIEPP, núm. 90. República de Argentina: Centro

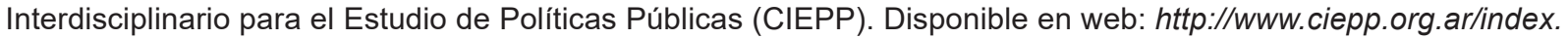
php/documentosdetrabajo1/465-multimedia-90.

BERTRANOU, F. (coord.) (2010): Aportes para la construcción de un piso de protección social en Argentina: el caso de las asignaciones familiares. Proyecto ARG/06/M01/FRA Una respuesta nacional a los desafíos de la globalización, Cooperación Técnica para el Desarrollo de la República Francesa. Ciudad Autónoma de Buenos Aires: Oficina de la OIT en Argentina. Disponible en web: https://www.ilo.org/wcmsp5/groups/public/---americas/---ro-lima/---ilobuenos_aires/documents/publication/wcms_bai_pub_139.pdf.

CECCHINI, S.; ATUESTA, B. (2017): "Programas de transferencias condicionadas en América Latina y el Caribe. Tendencias de cobertura e inversión”, en Comisión Económica para América Latina y el Caribe (CEPAL), Serie Políticas Sociales, núm. 224. Disponible en web: https://repositorio.cepal.org/bitstream/handle/11362/41811/1/ S1700419_es.pdf.

CENA, R.; CHAHBENDERIAN, F. (2015): "El abordaje estatal de la pobreza en Programas de Transferencias Monetarias Condicionadas", en Revista Latinoamericana de Ciencias Sociales, Niñez y Juventud, vol. 13, núm. 1, págs. 123-136. Disponible en web: https://ri.conicet.gov.ar/bitstream/handle/11336/51371/CONICET_Digital_ Nro.617695cc-df88-4496-bf0b-72f75a138271_A.pdf?sequence=2\&isAllowed=y.

CUFRÉ, D. (2010): "Antes hacían el fuego del asado con el parquet”, en Diario Página12. Edición 16 de Mayo del año 2010. Disponible en web: https://www.pagina12.com.ar/diario/economia/2-145746-2010-05-16.html.

DANANI, C. (2013): "El Sistema de Protección Social Argentino entre 2002 y 2013: buscando el modelo que nunca tuvo", en Revista Uruguaya de Ciencia Política, vol. 22, núm. 2, págs. 145-169. Disponible en web: http://www. scielo.edu.uy/pdf/rucp/v22nspe/v22nspe07.pdf.

DEL TEDESCO LINS, M. ${ }^{a}$ A. (2010): "Transferencias Condicionadas: Brasil y el Programa Bolsa Familia”, en /I Seminario Internacional de Política Social. Transferencias condicionadas como estrategia para la reducción de la pobreza. Lecciones aprendidas en América Latina, págs. 43-54. Guatemala: Universidad Rafael Landívar y Konrad Adenauer Stiftung. Disponible en web: https://www.kas.de/c/document_library/get_file?uuid=5abb0e8a0845-6bc2-c2c9-377c6ccec9d2\&groupld=252038.

DIARIO PÁGINA 12 (2013): “EI Plan Social que cambió a Brasil”, en Página12. Edición 31 de Octubre del año 2013. Disponible en web: http://www.pagina12.com.ar/diario/elmundo/4-232519-2013-10-31.html.

FERNÁNDEZ DE KIRCHNER, C. (2009): "Palabras de Cristina Fernández de Kirchner anunciando la Asignación Universal por Hijo", en Sitio Oficial de Cristina Fernández de Kirchner. Unidad Ciudadana. Disponible en web: https:// www.cfkargentina.com/palabras-de-cristina-fernandez-de-kirchner-anunciando-la-asignacion-universal-por-hijo/.

GARCÉS, L.; ESTÉVEZ, M. F. (2012): "Los sentidos otorgados a la condicionalidad en salud y educación de la Asignación Universal por Hijo. La mirada de los agentes del Estado", en Libro de Ponencias del V Congreso Mundial por los Derechos de la Infancia y la Adolescencia: Infancia, Adolescencia y Cambio Social. San Juan (República de Argentina), 15 a 19 de octubre de 2012. República de Argentina: Ministerio de Desarrollo Social, Presidencia de la Nación y Ministerio de Desarrollo Humano y Promoción Social, Gobierno de San Juan. Disponible en web: https://es.scribd.com/doc/114223067/Libro-de-Ponencias-V-Congreso-Mundial-Por-LosDerechos-de-La-Infancia-y-Adolescencia-Argentina-2012.

GONZÁLEZ, C. (2012): "Nuevas tendencias del Sistema de Protección Social en Argentina en el nuevo milenio: ¿hacia un nuevo paradigma?", en Revista Textos y Contextos (Porto Alegre), vol. 11, núm. 2, págs. 247-257. Disponible en web: http://revistaseletronicas.pucrs.br/ojs/index.php/fass/article/viewFile/12693/8635.

HEVIA DE LA JARA, F. (2009): "De Progresa a Oportunidades: efectos y límites de la corriente cívica en el gobierno

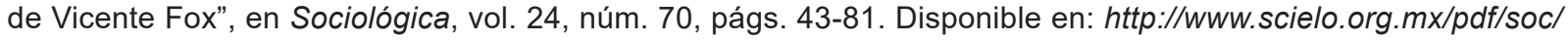
v24n70/v24n70a3.pdf.

HEVIA DE LA JARA, F. (2016) "Los riesgos de los programas de transferencia condicionadas y la construcción de ciudadanía: el caso de Progresa / Oportunidades de México", en Reflexión Política, vol. 18, núm. 35, págs. 28-41. Disponible en web: https://www.redalyc.org/pdf/110/11046399004.pdf. DOI: https://doi. org/10.29375/01240781.2462.

HINTZE, S. (2015): "La Asignación Universal por Hijo en el marco de la política y la seguridad social en Argentina", en Revista Debate Público. Reflexión de Trabajo Social, vol. 5, núm. 9, págs. 57-68. Disponible en web: http:// trabajosocial.sociales.uba.ar/wp-content/uploads/sites/13/2016/03/08_Hintze_9.pdf.

KLIKSBERG, B. y NOVACOVSKY, I. (dirs.) (2015): El gran desafío. Romper la trampa de la desigualdad desde la infancia: Aprendizajes de la Asignación Universal por Hijo. Ciudad Autónoma de Buenos Aires: Biblos.

LO VUOLO, R. M. (2009): “Asignación por Hijo”, en Análisis de Coyuntura CIEPP, núm. 21. Ciudad Autónoma de Buenos Aires: Centro Interdisciplinario para el Estudio de Políticas Públicas (CIEPP). Disponible en web: http:// www.ciepp.org.ar/images/N\%C2\%BA_21__Lo_Vuolo_-_Noviembre_2009.pdf.

LO VUOLO, R. M. (2010): "Las perspectivas del ingreso ciudadano en América Latina. Un análisis en base al «Programa Bolsa Familia» de Brasil y a la «Asignación Universal por Hijo para la Protección Social» de Argentina", 
GAPP. Nueva Época - N. 23, mayo-octubre 2020 - ISSN: 1989-8991 - DOI: 10.24965/gapp.i23.10717 - [Págs. 111-134]

Transferencia Condicionada de Ingresos en Argentina: una mirada hacia los orígenes de la Asignación Universal por Hijo ...

Melisa Cristina Vargas

en Documento de Trabajo CIEPP, núm. 76. Ciudad Autónoma de Buenos Aires: Centro Interdisciplinario para el Estudio de Políticas Públicas (CIEPP). Disponible en web: http://www.ciepp.org.ar/images/ciepp/docstrabajo/ doc\%2076.pdf.

LUKIN, T. (2012): “Asignación...”, en Diario Página12. Edición 29 de Enero del año 2012. Disponible en web: http:// www.pagina12.com.ar/diario/suplementos/cash/17-5755-2012-01-29.html.

MAZZOLA, R. (2015): Nuevo Paradigma. La Asignación Universal por Hijo en la Argentina. Ciudad Autónoma de Buenos Aires: Prometeo.

MARTÍNEZ FRANZONI, J.; VOOREND, K. (2008): "Transferencias Condicionadas e Igualdad de Género, ¿Blancos, Negros o Grises?", en Revista de Ciencias Sociales Universidad de Costa Rica, vol. IV, núm. 122, págs. 115131. Disponible en web: https://www.redalyc.org/articulo.oa?id=15312992010. DOI: https://doi.org/10.15517/rcs. v0i122.9879.

MICHA, A. (2019): "Usos y administración de la Asignación Universal por Hijo (AUH): entre el «deber ser» y la autonomía económica de las mujeres", en Trabajo y Sociedad, núm. 32, págs. 359-386. Disponible en web: https://www.unse.edu.ar/trabajoysociedad/32\%20MICHA\%20ARIELA\%20Asignacion\%20Universal\%20por\%20 Hijo,\%20AMBA,\%20Genero.pdf.

MINISTERIO DE TRABAJO, EMPLEO Y SEGURIDAD SOCIAL, PRESIDENCIA DE LA NACIÓN y OFICINA DE PAÍS DE LA OIT PARA LA ARGENTINA (2012): Macroeconomía, empleo e ingresos: debates y políticas en Argentina frente a la crisis internacional 2008-2009. Ciudad Autónoma de Buenos Aires: Oficina de la OIT en Argentina. Disponible en web: $h$ ttps://www.argentina.gob.ar/sites/default/files/macroeconomia empleo e ingresos.pdf.

MINISTERIO DE TRABAJO, EMPLEO Y SEGURIDAD SOCIAL, PRESIDĒNCIA DE LA NACIÓN (2014): Protección y Seguridad Social en la Argentina. Resultados de la encuesta nacional de protección y seguridad social 2011. ENAPROSS. Ciudad Autónoma de Buenos Aires: Ministerio de Trabajo, Empleo y Seguridad Social, Presidencia de la Nación. Disponible en web: http://www.trabajo.gob.ar/downloads/estadisticas/enapross/Libro_ ENAPROSS_interior.pdf.

MORENO, L. y SERRANO PASCUAL, A. (2007) “Europeización del Bienestar y activación”, en Política y Sociedad, vol. 44, núm. 2, págs. 31-44. Disponible en web: https://revistas.ucm.es/index.php/POSO/article/view/ POSO0707230031A/22251.

MOLYNEUX, M. (2005) "Más allá del debate sobre el trabajo doméstico", en RODRíGUEZ, D.; COOPER, J. (coords.): El debate sobre el trabajo doméstico. Antología. México D. F.: Universidad Nacional Autónoma de México, Instituto de Investigaciones Económicas, Escuela Nacional de Trabajo Social y Centro de Investigaciones Interdisciplinarias en Ciencias y Humanidades. Disponible en web: https://edisciplinas.usp.br/pluginfile.php/4097116/mod_resource/ content/4/El\%20trabajo\%20domestico.Gardiner\%2C\%20Seccombe\%20et\%20al\%20\%282005\%29pdf.pdf.

MOLYNEUX, M. (2006): "Mothers at the service of the New Poverty Agenda: Progresa / Oportunidades, Mexico's condicional transfer programme", en Social Policy \& Administration, vol. 40, núm. 4, págs. 425-449. Disponible en web: https://www.researchgate.net/publication/227651059_Mothers_at_the_Service_of_the_New_Poverty Agenda_ProgresaOportunidades_Mexico's_Conditional_Transfer_Programme. DÖl: https://doi.org/10.1111/j.14679515.2006.00497.x.

OBSERVATORIO DE LA SEGURIDAD SOCIAL (2012): La Asignación Universal por Hijo para la protección social en perspectiva. La política pública como restauradora de derechos. Ciudad Autónoma de Buenos Aires: Administración Nacional de la Seguridad Social (ANSES), Ministerio de Trabajo, Empleo y Seguridad Social, Presidencia de la Nación. Disponible en web: http://observatorio.anses.gob.ar/archivos/publicaciones/OBS000255\%20-\%20AUH\%20en\%20Perspectiva.pdf.

PERRY, G. E.; ARIAS, O. S.; LÓPEZ, J. H., MALONEY, W. F.; SERVÉN L. (2006): Reducción de la pobreza y crecimiento: Círculos virtuosos y círculos viciosos. Bogotá: Banco Mundial y Mayol Ediciones. Disponible en web: http://documentos.bancomundial.org/curated/es/952741468276883172/pdf/353480PUB00SPA00Box0361520B0P UBLICO.pdf.

PAUTASSI, L.; ARCIDIÁCONO, P.; STRASCHNOY, M. (2013): "Asignación Universal por Hijo para la Protección Social de la Argentina. Entre la satisfacción de Necesidades y el Reconocimiento de Derechos”, en Comisión Económica para América Latina y el Caribe (CEPAL), Serie Políticas Sociales, núm. 184. Disponible en web: https://repositorio.cepal.org/bitstream/handle/11362/6193/1/LCL3662_es.pdf.

REPÚBLICA DE ARGENTINA (1996): Régimen de Asignaciones Familiares. Ley núm. 24.714. Ciudad Autónoma de Buenos Aires: Ministerio de Justicia y Derechos Humanos, Presidencia de la Nación. Disponible en web: http:// servicios.infoleg.gob.ar/infoleglnternet/anexos/35000-39999/39880/texact.htm.

REPÚBLICA DE ARGENTINA (2003): Creación del Programa para la Creación de Seguros de Maternidad e Infancia Provinciales. Resolución núm. 198/03. Ministerio de Salud. Ciudad Autónoma de Buenos Aires: Ministerio de Justicia y Derechos Humanos, Presidencia de la Nación. Disponible en web: http://www.saij.gob.ar/creacionprograma-para-creacion-seguros-maternidad-infancia-provinciales-creacion-programa-para-creacion-segurosmaternidad-infancia-provinciales-nv11087-2003-08-15/123456789-0abc-780-11ti-Ipssedadevon?q=\%28numeronorma\%3A198\%20AND\%20fecha\%3A2003\%29\%20\&o=0\&f=Total\%7CTipo\%20de\%20Documento/ Legislaci\%F3n/Resoluci\%F3n\%7CFecha\%7COrganismo/MS\%7CPublicaci\%F3n\%7CTema\%7CEstado\%20 de\%20Vigencia\%7CAutor\%7CJurisdicci\%F3n\&t=1. 
GAPP. Nueva Época - N. 23, mayo-octubre 2020 - ISSN: 1989-8991 - DOI: 10.24965/gapp.i23.10717 - [Págs. 111-134]

Transferencia Condicionada de Ingresos en Argentina: una mirada hacia los orígenes de la Asignación Universal por Hijo ...

Melisa Cristina Vargas

REPÚBLICA DE ARGENTINA (2005): Ley de Protección Integral de los Derechos de las Niñas, Niños y Adolescentes. Ley núm. 26.061. Disposiciones generales. Objeto. Principios, Derechos y Garantías. Sistema de Protección Integral de los Derechos de las Niñas, Niños y Adolescentes. Órganos Administrativos de Protección de Derechos. Financiamiento. Disposiciones complementarias. Ciudad Autónoma de Buenos Aires: Ministerio de Justicia y Derechos Humanos, Presidencia de la Nación. Disponible en web: http://servicios.infoleg.gob.ar/infolegInternet/ anexos/110000-114999/110778/norma.htm.

REPÚBLICA DE ARGENTINA (2007): Decreto núm. 897/2007. Sistema Integrado de Jubilaciones y Pensiones. Creación y Fines del Fondo de Garantía de Sustentabilidad del Régimen Previsional Público de Reparto. Integración. Organización. Ciudad Autónoma de Buenos Aires: Ministerio de Justicia y Derechos Humanos, Presidencia de la Nación. Disponible en web: http://servicios.infoleg.gob.ar/infoleglnternet/ anexos/130000-134999/130056/norma.htm.

REPÚBLICA DE ARGENTINA (2009): Administración Nacional de la Seguridad Social (ANSES). Asignaciones Familiares. Resolución núm. 393/2009. Asignación Universal por Hijo para Protección Social. Reglamentación. Ciudad Autónoma de Buenos Aires: Ministerio de Justicia y Derechos Humanos, Presidencia de la Nación. Disponible en web: http://servicios.infoleg.gob.ar/infoleglnternet/anexos/160000-164999/161339/norma.htm.

REPÚBLICA DE ARGENTINA (2009): Decreto núm. 1602/2009. Asignaciones Familiares. Incorpórase el Subsistema no Contributivo de Asignación Universal por hijo para Protección Social. Ciudad Autónoma de Buenos Aires: Ministerio de Justicia y Derechos Humanos, Presidencia de la Nación. Disponible en web: http://servicios.infoleg. gob.ar/infolegInternet/anexos/155000-159999/159466/norma.htm.

REPÚBLICA DE ARGENTINA (2010): Administración Nacional de la Seguridad Social (ANSES). Asignaciones Familiares. Resolución núm. 132/2010. Asignación Universal por Hijo para Protección Social. Libreta Nacional de Seguridad Social, Salud y Educación. Formalidades y plazos. Ciudad Autónoma de Buenos Aires: Ministerio de Justicia y Derechos Humanos, Presidencia de la Nación. Disponible en web: https://www.argentina.gob.ar/ normativa/nacional/resoluci\%C3\%B3n-132-2010-164833/actualizacion.

REPÚBLICA DE ARGENTINA (2011): Decreto núm. 446/2011. Asignaciones Familiares. Modifícase la Ley núm. 24.714 en relación con la Asignación por Embarazo para Protección Social. Ciudad Autónoma de Buenos Aires: Ministerio de Justicia y Derechos Humanos, Presidencia de la Nación. Disponible en web: http://servicios.infoleg. gob.ar/infolegInternet/anexos/180000-184999/181250/norma.htm.

REPÚBLICA DE ARGENTINA (2012): Ministerio de Salud. Salud Pública. Resolución núm. 1.195/2012. Modifícanse denominación del "Programa para la Creación de Seguros de Maternidad e Infancia Provinciales" (Plan Nacer) creado por Resolución núm. 198/2003, por la de "Programa Nacional de Desarrollo de Seguros Públicos de Salud", y sus lineamientos. Ciudad Autónoma de Buenos Aires: Ministerio de Justicia y Derechos Humanos, Presidencia de la Nación. Disponible en web: http://servicios.infoleg.gob.ar/infoleglnternet/anexos/200000-204999/200893/ norma.htm.

REPÚBLICA DE ARGENTINA (2013): Decreto núm. 614/2013. Asignaciones Familiares. Establécense los rangos, topes y montos de las Asignaciones Familiares, contempladas en la Ley núm. 24.714. Suplemento adicional. Ciudad Autónoma de Buenos Aires: Ministerio de Justicia y Derechos Humanos, Presidencia de la Nación. Disponible en web: http://servicios.infoleg.gob.ar/infoleglnternet/anexos/215000-219999/215701/norma.htm.

REPÚBLICA DE ARGENTINA (2014): Código Civil y Comercial de la Nación. Aprobado por la Ley 26.994. Promulgado según el Decreto 1795/2014. Ciudad Autónoma de Buenos Aires: Ministerio de Justicia y Derechos Humanos, Presidencia de la Nación. Disponible en web: http://www.saij.gob.ar/docs-f/codigo/Codigo_Civil_y_ Comercial_de_la_Nacion.pdf.

REPÚBLICA DE ARGENTINA (2015): Decreto núm. 504/2015. Régimen de Asignaciones Familiares. Ley núm. 24.714. Modificación. Ciudad Autónoma de Buenos Aires: Ministerio de Justicia y Derechos Humanos, Presidencia de la Nación. Disponible en web: http://servicios.infoleg.gob.ar/infoleglnternet/anexos/245000-249999/245619/norma.htm.

REPÚBLICA DE ARGENTINA (2015): Régimen de Asignaciones Familiares. Ley núm. 27.160. Asignaciones Familiares. Movilidad. Ciudad Autónoma de Buenos Aires: Ministerio de Justicia y Derechos Humanos, Presidencia de la Nación. Disponible en web: http://servicios.infoleg.gob.ar/infoleglnternet/anexos/245000-249999/249221/norma.htm.

REPÚBLICA FEDERATIVA DE BRASIL (2004): Ley núm. 10.836. Crea el Programa Bolsa de Familia y otras medidas. Brasilia: Presidencia de la República Federativa de Brasil. Disponible en web: http://www.pla nalto.gov. br/ccivil_03/_ato2004-2006/2004/lei/l10.836.htm.

ROCA, E.; GOLBERT, L.; LANARI, M. E. (2012): ¿Piso o sistema integrado de protección social? Una mirada desde la experiencia argentina. Buenos Aires: Ministerio de Trabajo, Empleo y Seguridad Social, Secretaría de Seguridad Social. Disponible en web: https://www.argentina.gob.ar/sites/default/files/pisoosistema.pdf.

RODRÍGUEZ ENRÍQUEZ, C. (2007): "Economía del cuidado, equidad de género y nuevo orden económico internacional en Del Sur al Norte: economía política del orden económico internacional emergente”, en GIRON, A.; CORREA, E. (coords.): Del Sur hacia el Norte: Economía política del orden económico internacional emergente, págs. 229-240. Buenos Aires: Consejo Latinoamericano de Ciencias Sociales (CLACSO). Disponible en web: http://biblioteca.clacso.edu.ar/clacso/sur-sur/20100705083822/22RodriguezE.pdf.

RODRÍGUEZ ENRÍQUEZ, C. (2011): "Programas de Transferencias Condicionadas de Ingreso e Igualdad de Género. ¿Por dónde anda América Latina?”, en Comisión Económica para América Latina y el Caribe (CEPAL), Serie 
Mujer y Desarrollo, núm. 109. Disponible en web: https://repositorio.cepal.org/bitstream/handle/11362/5836/1/ S1100854_es.pdf.

RODRÍGUEZ ENRÍQUEZ, C. (2012): “La cuestión del cuidado: ¿El eslabón perdido del análisis económico?”, en Revista CEPAL, núm. 106, págs. 23-36. Disponible en web: https://repositorio.cepal.org/bitstream/ handle/11362/11524/106023036_es.pdf.

RODRÍGUEZ ENRÍQUEZ, C. (2014): "El trabajo de cuidado no remunerado en Argentina: un análisis de la evidencia del módulo de Trabajo no Remunerado", en Documentos de Trabajo "Políticas Públicas y Derecho al Cuidado», núm. 2, págs. 1-24. Buenos Aires: Asociación por los Derechos Civiles (ADC), Centro Interdisciplinario para el Estudio de Políticas Públicas (CIEPP) y Equipo Latinoamericano de Justicia y Género (ELA). Disponible en web: https://ri.conicet.gov.ar/bitstream/handle/11336/34802/CONICET_Digital_Nro.0d0828bc-d5d1-455c-9b1d59cdd40cb35d_A.pdf?sequence=2\&isAllowed=y.

SALVIA, A., POY, S. y VERA, J. (2015): "La política social y sus efectos sobre la pobreza y la desigualdad durante distintos regímenes socioeconómicos en Argentina (1992-2012)", en Seminario Internacional Temas de la Política Social en Argentina, México y Uruguay. México D. F., 23 y 24 de febrero de 2015. Centro de Estudios Sociológicos de El Colegio de México. Disponible en web: https://www.aacademica.org/agustin.salvia/323.pdf.

TANCARA, C. (1993): “La investigación documental”, en Temas Sociales, núm. 17, págs. 91-106. Disponible en web: http://www.revistasbolivianas.org.bo/scielo.php?script=sci_arttext\&pid=S0040-29151993000100008\&/ng=es\&nrm=iso.

VARELA, N. (2005): Feminismo para principiantes. Barcelona. Ediciones B.

VARGAS, M. (2018): "AUH: de política reparadora a contención social del trabajador", en Nuestras Voces. Edición 3 de Noviembre del año 2018. Disponible en web: http://www.nuestrasvoces.com.ar/mi-voz/auh-de-politica-reparadoraa-contencion-social-del-trabajador/.

VILAS, C. M. ${ }^{a}$ (2011): Después del Neoliberalismo: Estado y procesos políticos en América Latina. Lanús: Ediciones de la UNLa (Universidad Nacional de Lanús).

VILLATORO, P. (2007): "Las Transferencias Condicionadas en América Latina: Luces y sombras", en Documento de la CEPAL para el Seminario Internacional "Evolución y Desafíos de los programas de transferencias condicionadas». Brasilia, 20 y 21 de noviembre de 2007. Disponible en web: https://www.cepal.org/sites/default/ files/events/files/2007-nov-cepal_pablovillatoro_ptc.pdf. 